\title{
El género Eurysternus Damlan, 1824 (Coleoptera: Scarabaeidae: Oniticellini) del departamento de Loreto, Perú
}

\author{
The genus Eurysternus Dalman, 1824 (Coleoptera: Scarabaeidae: Oniticellini) from Loreto \\ department, Peru
}

\section{Luis Figueroa* \\ https://orcid.org/0000-0002-1404-6195 \\ Luis_thecell@hotmail.com \\ Fernando Paz \\ https://orcid.org/0000-0002-6331-4416 \\ fernandopaz683@gmail.com \\ *Corresponding author}

1 Universidad Nacional Mayor de San Marcos, Museo de Historia Natural, Departamento de Entomología, Apartado 14-0434, Lima 14, Perú

\section{Citación}

Figueroa L, Paz F. 2021. El género Eurysternus Damlan, 1824 (Coleoptera: Scarabaeidae: Oniticellini) del departamento de Loreto, Perú. Revista peruana de biología 28(especial): e21919 001- 018 (Diciembre 2021). doi: http://dx.doi.org/10.15381/rpb.v28ies pecial.21919

\section{Presentado: $\quad 09 / 02 / 2021$ \\ Aceptado: $\quad 10 / 08 / 2021$ \\ Publicado online: 30/12/2021}

Editor:

Leonardo Romero

\section{Resumen}

Presentamos 13 especies del género Eurysternus (Coleoptera: Scarabaeidae: Oniticellini) del departamento de Loreto - Perú. Registramos por primera vez para Perú a la especie Eurysternus ventricosus Gill, 1990. Además, proporcionamos fotos de los habitus y aedeagus y mapas de distribución de las especies encontradas en este departamento.

\section{Abstract}

Thirteen species of the genus Eurysternus (Coleoptera: Scarabaeidae: Oniticellini) occurring in Loreto Department - Peru are presented. Eurysternus ventricosus Gill, 1990 is recorded for the first time in Peru. Additionally, the habitus and aedeagus are illustrated, and distribution records for all the species found in the department are presented.

Palabras clave:

Escarabajo pelotero, coprófagos, Amazonia, Neotrópico, nuevo registro.

Keywords:

Dung beetle, scarabs, Amazon, Neotropic, new records.

\section{Introducción}

La subfamilia Scarabaeinae (Coleoptera: Scarabaeidae), conocidos comúnmente como escarabajos coprófagos o peloteros, es un grupo muy extendido al nivel mundial, el cual presenta hábitos muy peculiares debido al uso de heces para su alimentación y anidamiento, además de mostrar comportamientos reproductivos particulares (Cambeforti \& Hanski 1991). Estos escarabajos además de cumplir ciertos roles ecológicos como reciclaje de nutrientes, dispersores de semillas, controladores de plagas son considerados como bioindicadores de hábitats fragmentados, debido a su alta sensibilidad a cambios o perturbaciones en sus hábitats (Nichols et al. 2007), e incluso son mencionados como insectos de importancia forense (Nichols et al. 2008, Almeida \& Mise 2009). Esta subfamilia ha sido ampliamente utilizada en estudios de biodiversidad debido a que es un grupo claramente monofilético con una taxonomía lo suficientemente conocida, lo que se suma a su fácil y poco costosa metodología de muestreo (Favila \& Halffter 1997, Villareal et al. 2006). 
El género Eurysternus Dalman, 1824 tiene distribución netamente neotropical, desde México hasta Argentina, aunque se estima que su rango de distribución podría ampliarse desde el sur de los Estados Unidos, pasando por el Caribe y el sureste de América del Sur (Génier 2009, Camero \& Lobo 2012). Actualmente, el género cuenta con 53 especies descritas (Génier 2009), de las cuales 19 especies han sido registradas en Perú (Ratcliffe et al. 2015), aunque ninguna de ellas es endémica. El género tiene una forma alargada muy diferente a los otros miembros de la subfamilia Scarabaeinae, debido a la disposición de las coxas, lo que afecta directamente al modo de formar sus bolas de heces (Huerta et al. 2005).

El departamento de Loreto, ubicado al noreste de Perú, está constituido por cuatro provincias biogeográficas: Ucayali, Napo, Imeri y Madeira (Morrone 2014) e influenciado directamente por el río Amazonas. Siendo el departamento con mayor extensión en Perú, con $368851 \mathrm{~km}^{2}$, también registra una alta diversidad biológica en sus bosques (Pitman et al. 2013). Sin embargo, los trabajos sobre coleópteros coprófagos en Loreto son escasos, abarcando aspectos ecológicos de algunas especies y preferencias de substratos o cebos (Ampudia \& Estrella 2020), variaciones estacionales (Sulca \& Huamantinco 2016) y estudios de biodiversidad (Ampudia et al. 2020). También, podemos mencionar los trabajos taxonómicos de Figueroa et al. (2012, 2014), que proporcionan información de la distribución de escarabajos de la tribu Phanaeini; y el de Ampudia et al. (2012) que reporta a Tetramereia convexa (Harold, 1869) como un nuevo registro para el Perú.
El presente trabajo refiere la presencia del género Eurysternus (Coleoptera: Scarabaeidae: Oniticellini) en el departamento de Loreto - Perú, proporcionando una diagnosis de las especies, mapas de distribución, imágenes del hábitus y de sus aedeagus.

\section{Material y métodos}

Para el presente trabajo examinamos y determinamos taxonómicamente 657 ejemplares, pertenecientes a la colección entomológica del Museo de Historia Natural de la Universidad Nacional Mayor de San Marcos, Perú (MUSM). La terminología empleada en la clasificación general, las diagnosis y el ordenamiento de especies están basados en Génier (2009). Para cada especie se cita autor y año (respetamos la ortografía original). Además, se presenta una diagnosis de cada especie, la distribución en Perú y en América.

\section{Resultados}

\section{TRIBU ONITICELLINI KOLBE, 1905}

\section{SUBTRIBU EURYSTERNINA VULCANO, MARTÍNEZ \& PEREIRA, 1961}

\section{GENERO EURYSTERNUS DAMLAN 1824}

\section{GRUPO CARIBAEUS}

\section{Eurysternus caribaeus (Herbst, 1789)}

(Figs. 1a, 1b, 1c, Fig. 17).

Scarabaeus caribaeus Herbst, 1789: 300.

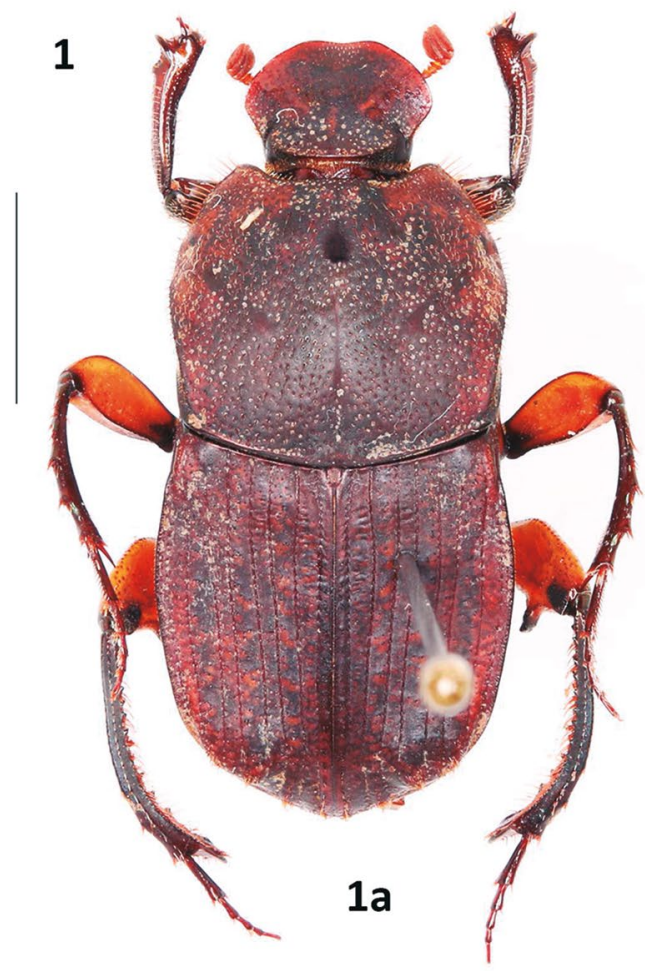

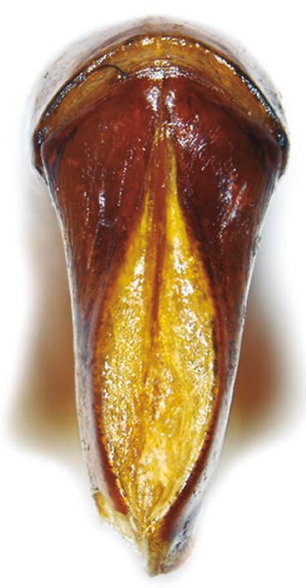

1b

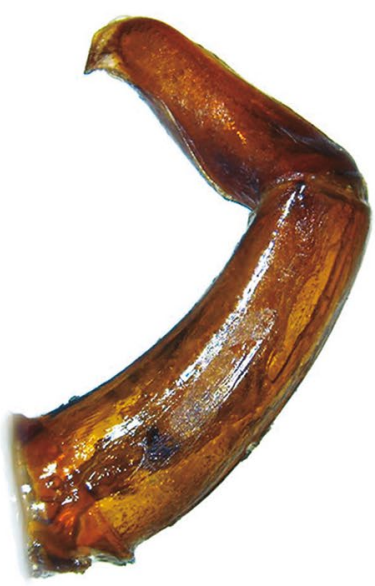

1c

Figura 1. Eurysternus caribaeus Herbst. 1a) Habitus dorsal del macho. 1b) Aedeagus vista frontal. 1c) Vista lateral. vista lateral. 
Diagnosis: largo: 13.5 - $18 \mathrm{~mm}$, ancho: 4.5 -7.5 mm. Coloración anaranjada a marrón rojiza oscurecida con un patrón de manchas marrones irregulares en cabeza, pronoto y élitros, las manchas del pronoto se notan más densas y cubren mayor superficie de este; coloración de los fémures anaranjado a marrón rojizo, las tibias marrones verdoso, con reflejo verde metálico. Cabeza con puntuación ocelada, más grande y confluente en la frente y genas, y fina en el ápice del clípeo; pronoto con puntuación ocelada moderadamente densa, con sedas cortas y curvadas, región pre apical con un callo lustroso, alrededor de estas 4 callosidades de tono mate, márgenes laterales algo redondeados, finamente aquillados, esquinas posteriores sin un diente; lóbulo del metasterno con puntuaciones oceladas, la región posterior con 2 carenas pequeñas paralelas. Élitros con interestrías cubiertas con sedas diminutas, ápices de las interestrías 3, 5 y 7 con mechones de sedas muy cortas. Tibias anteriores ligeramente curvadas, con un tubérculo ventral fuerte; anterior a este, una fila de tubérculos diminutos; margen externo de la tibia con 3 dientes poco desarrollados en machos y más desarrollados en hembras, coxas posteriores con franjas claras y oscuras intercaladas, fémur posterior con un diente agudo distal en machos, más central y corto en hembras, tibias posteriores moderadamente curvadas en machos, más rectas en hembras, cara interna con una fila de tubérculos agudos, ápice de la tibia con el espolón fusionado. Aedeagus ver Fig. 1b y Fig. 1c.

Material examinado: 100 especímenes examinados, 57 machos y 43 hembras.

PERÚ: Loreto: (24) Río Ungumayo, $171 \mathrm{~m}$, $4^{\circ} 08^{\prime} 08.16^{\prime \prime S}, 76^{\circ} 11^{\prime} 03.48^{\prime \prime W}, 29-30 . x i .2009$; (8) río Ungumayo, $137 \mathrm{~m}, 4^{\circ} 07^{\prime} 27.48 " \mathrm{~S}, \quad 76^{\circ} 11^{\prime} 26.52^{\prime \prime} \mathrm{W}$, 30.xi-1.x.2009; (1) río Ungumayo, $144 \mathrm{~m}, 4^{\circ} 12^{\prime} 36^{\prime \prime} \mathrm{S}$, 75²9'24"W, 24.iii.2010; (12) Iquitos, Km 28 SO Iquitos, RN Allpahuayo Mishana, $148 \mathrm{~m}, 3^{\circ} 58^{\prime} 21.80 " \mathrm{~S}$, 73²5'29.12"W, 29-31.x.2010; (9) Iquitos, Km 24.6 SO Iquitos, RN Allpahuayo, Mishana, $137 \mathrm{~m}, 3^{\circ}{ }^{\circ} 7^{\prime} 10.3^{\prime S}$, 73⒉'25.34"W, 29-31.x.2010; (1) Requena, Bretaña, Lote 95,102 m, 5¹4'42.48"S, 74²19'40.55"W, 4.viii.2018; (1) Requena, Bretaña, Lote 95, 112 m, 5¹4'52.16"S, 74¹9'47.46"W, 4.viii.2018;(1) Requena, Bretaña, Lote95, 114 m, 5¹4'56.48"S, 74¹9'33"W, 4.viii.2018; (2) Trompeteros, Pihuicho, $143 \mathrm{~m}, 3^{\circ} 48^{\prime} 30.79^{\prime \prime} \mathrm{S}, 75^{\circ} 3^{\prime} 22.74 " \mathrm{~W}$, 25.ix-9.x.2015; (2) Punchana-Astoria, 103 m, 03³8'22"S, 73¹3'15.4"W, 4.iii.2014; (4) C.N. Morales Bermúdez, nr. río Trapiche, $87 \mathrm{~m}, 6^{\circ} 0^{\prime} 55.07^{\prime} \mathrm{S}, 7^{\circ} 4^{\prime} 59.95^{\prime \prime}$, 12.viii.2018; (3) Datem del Marañón, Morona, $125 \mathrm{~m}$, 3॰59'33.6"S, 77²13'53.86"W, 24-26.iii.2014; (4) Datem del Río Marañón, 132 m, 459'44.5"S, 76²18'25"W, 3.vii.2012; (2) Zona Reservada Sierra del Divisor, $172 \mathrm{~m}$, 6³0'28.53"S, 73³7'29.15"W, 03-06.v.2013; (2) Sierra del Divisor, $1 \mathrm{~km}$ río Trompeteros, $175 \mathrm{~m}, 6^{\circ} 28^{\prime} 31.7^{\prime \prime S}$, 74²'30"W, 18-19.x.2008; (1) Sierra del Divisor, 5 km del río Campanagua, 160 m, 6¹9'30"S, 7346'9"W, 20 21.x.2008; (2) Sierra del Divisor, cerca de Sarayacu, 195 m, 657'21.06"S, 74²'27.4"W, 10-11.x.2008; (1) Sierra del Divisor, río Hubuya, 199 m, 7³'20"S, 74²'9"W, 5-7.x.2006; (1) Sierra del Divisor, 2 km río Hubuya, 196 m, 659'31.8"S, 7359'26.07"W, 13-14.x.2008; (1) Sie- rra del Divisor, cerca del Río Punga, 222 m, 655'11.2"S, 7350'47"W, 22-24.x.2008; (1) río Ucayali, Sintico, 108 m, 59'11.83"S, 74'29.91"W, iv.2018; (1) río Ucayali, Nuevo Tarma, $82 \mathrm{~m}, 5^{\circ} 6^{\prime} 59.31$ "S, 74²'25.74"W, 15.iv.2018 (1) margen izquierda del río Ucayali, Contamana, $130 \mathrm{~m}, 7^{\circ} 27^{\prime} 49.42^{\prime \prime S}, 74^{\circ} 59^{\prime} 34.19^{\prime \prime W}$, 04-06. iv.2018; (1) Maynas, margen del río Urituyacu, Urarinas, $150 \mathrm{~m}, 4^{\circ} 08^{\prime} 50.05^{\prime} \mathrm{S}, 7^{\circ} 00^{\prime} 54.93^{\prime \prime W}$, 16.xi.2009; (1) Loreto: Maynas, río Itaya, 128-149 m, 549'0.20"S, 7347'18.3"W; (1) Loreto: Maynas, Qda. Aguablanca, 160-177 m, 0255'16.3"S, 7449'0.1"W; (2) Loreto: Requena, nr. Florida, $120 \mathrm{~m}, 5^{\circ} 27^{\prime} 34.5^{\prime \prime S}, 74^{\circ} 12^{\prime} 11^{\prime \prime W}$, 15-26.v.2014; (1) Requena, Puinahua, Bretaña, $114 \mathrm{~m}$, 5¹6'0.5"S, 74¹9'30"W, 19-20.v.2014; (1) Loreto, 140 m, 330'29.43"S, 75²5'7.95"W, iii.2018; (1) Alto Marañón, 138 m, 5¹2'47"S, 76²18'2.8"W, 20.vi.2012; (1) Loreto: 4 $\mathrm{km}$ de Qda. Tangarana, $175 \mathrm{~m}, 3^{\circ} 9^{\prime} 26.5^{\prime \prime} \mathrm{S}, 75^{\circ} 36^{\prime} 14.6^{\prime \prime} \mathrm{W}$, 25-26.xi.2008; (1) Calientillo (Contamana), $150 \mathrm{~m}$, 10.v.1985; (1) Maynas, Napo, río Curacay, Gaseoducto Barret, $1^{\circ} 35^{\prime} 13.38^{\prime \prime S}, 7^{\circ} 24^{\prime} 31.08^{\prime \prime W}, 16-18 . i i i .2008$; (1) Maynas, Alto río Pintayacu, $154 \mathrm{~m}, 02^{\circ} 40^{\prime} 24.8^{\prime \prime}$, 74²1'25.1"W, 14.ii.2009; (1) Maynas, Miraflores, 69 m, 347'4.8"S, 7341'43"W, 10.v.2012; (2) Sarayacu, CCPP Miguel Grau, 136 m, 6³7'8.60"S, 75³'49.80"W, 1-8.i.2013.

Comentario: esta especie presenta un rango altitudinal de 0 a los $3000 \mathrm{~m}$ de altitud, con una amplia distribución desde el sur de México hasta Argentina; en el Perú se encuentra en los departamentos de Amazonas, Loreto, Huánuco, Madre de Dios y Ucayali (Génier 2009), en el MUSM se encontraron especímenes de Cusco, Junín, Pasco y San Martin. En Loreto la especie ha sido encontrada todo el año. Por otra parte, la especie es colectada con trampas de cebo (bait trap) y trampas Malaise.

\section{Eurysternus hamaticollis Balthasar, 1939}

(Figs. 2a, 2b, 2c, Fig. 15).

\section{Eurysternus hamaticollis Balthasar, 1939: 113.}

Diagnosis: largo: 16 - $21 \mathrm{~mm}$, ancho: 6.5 - $9.5 \mathrm{~mm}$. Coloración y patrones de manchas muy similares a $E$. caribaeus. Cabeza con puntuación fina ligeramente mayor en la frente y genas; pronoto con puntuación ocelada pequeña moderadamente densa, con sedas finas cortas y curvadas, región pre apical con un callo lustroso de reflejos metálicos, y alrededor de este, 4 callosidades lustrosas con reflejos metálicos, márgenes laterales finamente aquillados, quilla desvaneciéndose en la mitad posterior y reapareciendo casi llegando al ápice; esquinas posteriores proyectadas hacia arriba a modo de dientes en machos, casi imperceptibles en hembras; lóbulo del metasterno con patrones de manchas oscuras que cubren gran parte, puntuación fina, la región posterior con una quilla corta en machos. Élitros con interestrías cubiertas por sedas diminutas, ápice de las interestrías 3, 5 y 7 con mechones de sedas muy cortas. Protibias rectas, ventralmente con un tubérculo distal fuerte, anterior a este, una carena crenulada; margen externo de la tibia con dos dientes poco desarrollados en machos y tres dientes de- 
sarrollados en hembras, metacoxas con franjas claras y oscuras intercaladas, metafémur con un diente central agudo en machos, y más corto en hembras, metatibias fuertemente curvadas en machos, más rectas en hembras, cara interna con una fila de tubérculos agudos, con el último tubérculo algo dilatado; ápice de la tibia con el espolón fusionado. Aedeagus ver las Fig. 2b y Fig. 2c.

Material examinado: 21 especímenes examinados, 14 machos y 7 hembras.

PERÚ: Loreto: (2) Río Urituyacu, Ayahuasca, $151 \mathrm{~m}$, $4^{\circ} 06^{\prime} \mathrm{S}, 7^{\circ} 0^{\prime} 36^{\prime \prime} \mathrm{W}, 19 . i i i .2010$; (1) río Urituyacu, CCNN San Juan de Abejaico, $150 \mathrm{~m}, 4^{\circ} 05^{\prime} 25^{\prime \prime S}, 76^{\circ} 0^{\prime} 36^{\prime \prime W}$, 17.xi.2009; (2) Sarayacu, CCPP Miguel Grau, $140 \mathrm{~m}$, 6³7'27.40"S, 75³'54.10"W, 7-13.xi.2013; (1) Sarayacu, CCPP Miguel Grau, 136 m, 6³7'8.60"S, 75³'49.80"W, 1-8.i.2013; (3) Maynas, margen del río Urituyacu, Urarinas, $143 \mathrm{~m}, 4^{\circ} 09^{\prime} 40.19^{\prime} \mathrm{S}, 7^{\circ} 00^{\prime} 49.22^{\prime \prime W}$, 18.xi.2009; (1) Maynas, margen del río Urituyacu, Urarinas, $150 \mathrm{~m}$, $4^{\circ} 08^{\prime} 50.05^{\prime} \mathrm{S}, 7^{\circ} 00^{\prime} 54.93^{\prime \prime W}, 16 . x i .2009$; (1) Maynas, Miraflores, 69 m, 347'4.8"S, 7341'43"W, 10.v.2012; (1)
Zona Reservada Sierra del Divisor, 155 m, 6²4'19.86"S, 7342'46.82"W, 27-30.iv.2013; (2) Sierra del Divisor, cerca de Sarayacu, 195 m, 657'21.06"S, 74²'27.4"W, 1011.x.2008; (2) Sierra del Divisor, 2 km río Hubuya, 196 m, 659'31.8"S, 7359'26.07"W, 13-14.x.2008; (2) Sierra del Divisor, $1 \mathrm{~km}$ río Trompeteros, $175 \mathrm{~m}, 6^{\circ} 28^{\prime} 31.7^{\prime \prime S}$, 74²'30"W, 18-19.x.2008; (1) Datem del Río Marañón, 132m, 459'44.5"S, 76²'18'"W, 3.vii.2012; (1) Prov. Requena, nr. Poblado de Iberia, $111 \mathrm{~m}, 5^{\circ} 40^{\prime} 2.7^{\prime \prime}$, 74¹2'20"W, 11-12.vi.2014; (1) río Ucayali, Nuevo Tarma 82m, 56'59.31"S, 74³'25.74"W, 15.iv.2018.

Comentario: esta especie presenta un rango altitudinal de 0 a los $1040 \mathrm{~m}$ de altitud, con una distribución restringida en la Amazonia, con una población registrada en Costa Rica, presumiblemente introducida. En Perú, esta especie se encuentra en los departamentos de Loreto y Madre de Dios (Génier 2009), en MUSM se registraron individuos de Cusco, Puno y Ucayali. En Loreto ha sido encontrada en enero, marzo, abril, mayo junio, julio, octubre y noviembre.

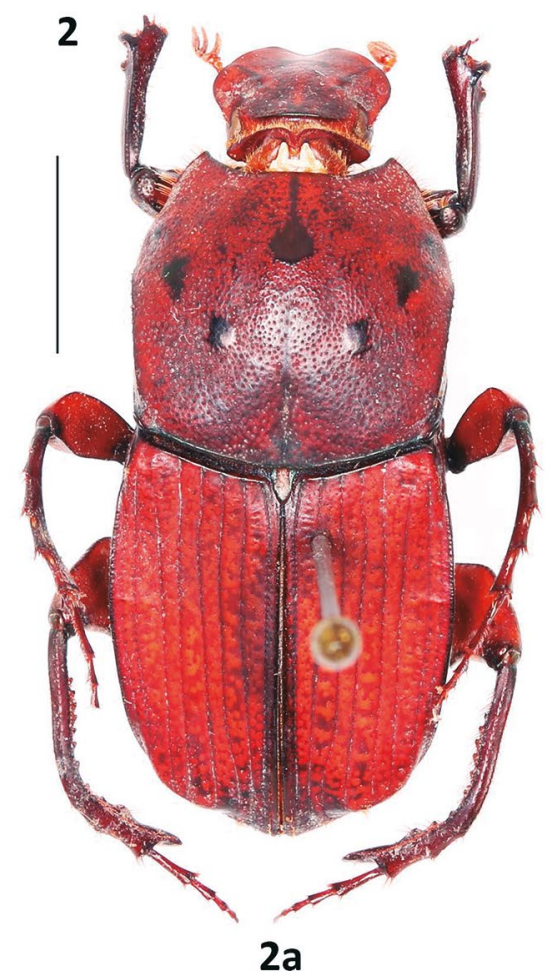

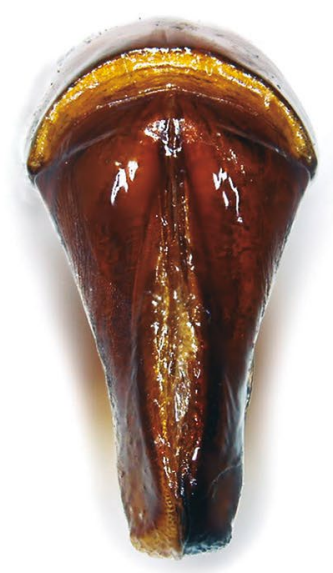

$2 b$

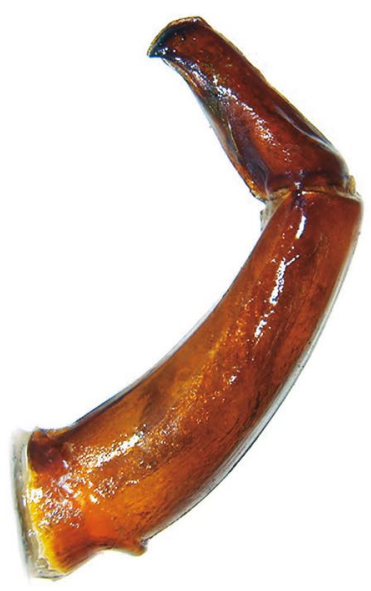

2c

Figura 2. Eurysternus hamaticollis Balthasar. 2a) Habitus dorsal del macho. 2b) Aedeagus vista frontal. 2c) Vista lateral.

\section{GRUPO CAYENNENSIS}

\section{Eurysternus cayennensis Castelnau, 1840}

(Figs. 3a, 3b, 3c, Fig. 14)

Eurysternus cayennensis Castelnau, 1840: 93.

Diagnosis: largo: 9 - $12 \mathrm{~mm}$, ancho: 3.5 - $5 \mathrm{~mm}$. Coloración marrón oscuro. Cabeza con puntuación pequeña, puntos ligeramente más grandes y ocelados en la parte posterior de la frente y alrededor de los ojos, sedas cortas insertadas en los puntos, 2 mechones de sedas más largas en el borde posterior de la frente y un mechón de sedas en el borde posterior de cada ojo. Pronoto con puntuaciones oceladas moderadamente densas, más grandes y confluentes en la parte media y posterior, sedas alargadas curvadas, insertadas casi en el centro de las puntuaciones del pronoto, ángulos anteriores del 
pronoto redondeados; lóbulo central del metasterno sin grandes puntuaciones oceladas, a lo mucho se nota algunas más cercanas a las mesocoxas. Élitros con microescultura alveolada, interestrías cubiertas por sedas erectas cortas, ápice de la primera interestría con una hilera corta de sedas largas, ápice de la tercera interestría con un mechón de setas y callo apical de la quinta y séptima interestría con una hilera de setas largas. Margen anterior del profémur carenado, en machos más desarrollados con un tubérculo pequeño, protibias algo curvadas, borde interno con aproximadamente ocho tubérculos, borde externo con tres dientes algo cortos en la región anterior, en hembras las protibias son más rectas y los dientes del borde externo están desarrollados; procoxas unicolores, profemur de los machos mayores con una o dos pequeñas gibosidades proximales en la región posterior, a veces también poco notoria, entre las cuales sale una hilera corta de sedas, en hembras es simple; metatibias de los machos moderadamente arqueadas, región interna de esta con una fila de tubérculos, en hembras son simples, ápice de las metatibias de los machos con espina móvil larga. Aedeagus ver Fig. 3b y Fig. 3c.

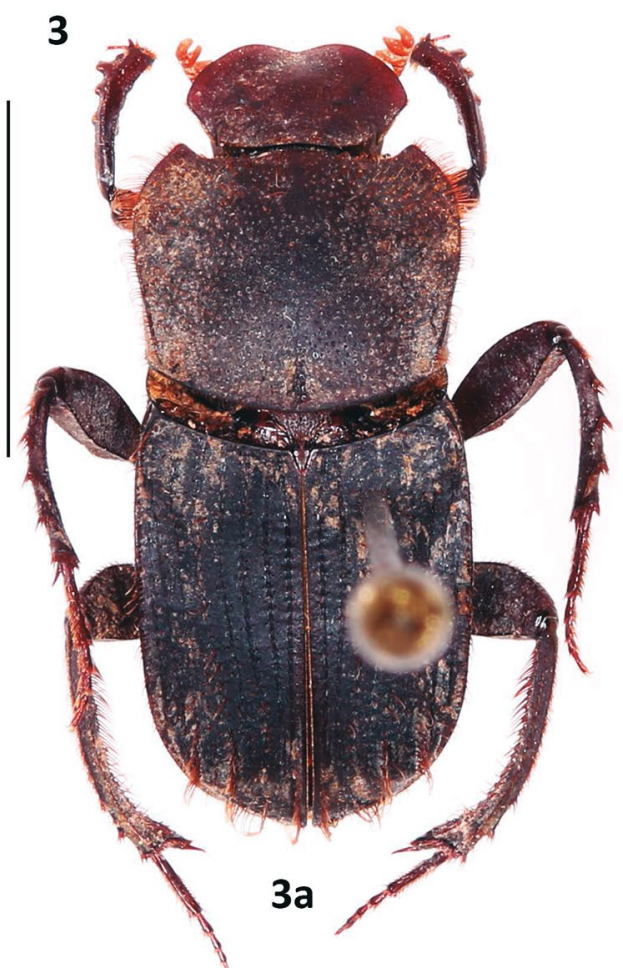

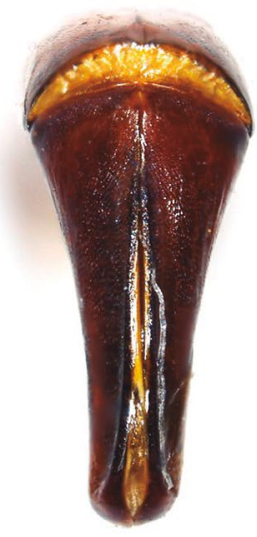

$3 b$

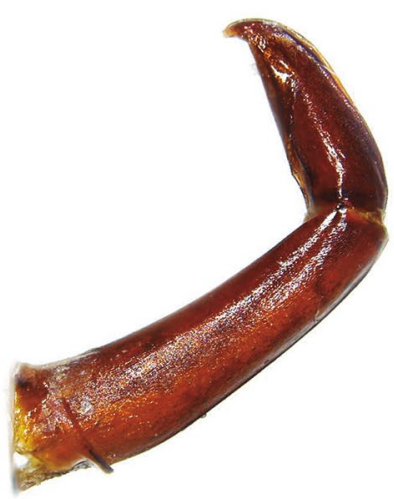

3c

Figura 3. Eurysternus cayennensis Castelnau. 3a) Habitus dorsal del macho. 3b) Aedeagus vista frontal. 3c) Vsta lateral. Barra de escala: $5 \mathrm{~mm}$.

Material examinado: 202 especímenes examinados, 124 machos y 78 hembras.

PERÚ: Loreto: (10) Iquitos, km 28 SO Iquitos, RN Allpahuayo Mishana, $148 \mathrm{~m}, 3^{\circ} 58^{\prime} 21.80^{\prime \prime S}, 73^{\circ} 25^{\prime} 29.12^{\prime \prime}$, 29-31.x.2010; (13) Iquitos, km 24.6 SO Iquitos, RN Allpahuayo Mishana, 137 m, 357'10.3"S, 7324'25.34"W, 2931.x.2010; (9) Río Nanay, 145 m, 3²5'58"S, 74²4'17"W, 29.i.2009; (7) Qda. Pucacuro, 175 m, 2²8'24.3"S, 7459'10.7"W, 13.ii.2009; (1) Maynas, Qda. Pucacuro, 186 -188 m, 2²8'52"S, 7458'48"W, 10.ii.2009; (6) Loreto: Maynas, Alto río Pintayacu, $154 \mathrm{~m}, 02^{\circ} 40^{\prime} 24.8^{\prime \prime} \mathrm{S}$, 7441'25.1"W, 14.ii.2009; (3) Maynas, Qda Aguablanca, $157 \mathrm{~m}, 02^{\circ} 55^{\prime} 45.3^{\prime \prime} \mathrm{S}, 74^{\circ} 48^{\prime} 20.8^{\prime \prime} \mathrm{W}, 24 . i .2009$; (5) Maynas, Qda Aguablanca, 160-177 m, 02 $55^{\prime} 16.3^{\prime \prime S}, 74^{\circ} 49^{\prime} 0.1^{\prime \prime W}$; (7) Maynas, Qda Aguablanca, 02 $55^{\prime} 26^{\prime \prime S}, 74^{\circ} 49^{\prime} 8.1^{\prime \prime W}$, 19.i.2009; (11) Maynas, 143 m, 3²4'2.3"S, 7459'51.9"W, 4.viii.2008; (14) Maynas, $138 \mathrm{~m}, 3^{\circ} 24^{\prime} 11.8^{\prime \prime S}, 7^{\circ} 59^{\prime} \mathrm{W}$, 4.viii.2008; (8) Sierra del Divisor, Nuevo Campanahua, $150 \mathrm{~m}, 6^{\circ} 29^{\prime} 29^{\prime \prime S}, 73^{\circ} 47^{\prime} 38.6^{\prime \prime} \mathrm{W}, 11-12 . i i i .2009$;
(14) Sierra del Divisor, Qda. Punga, 185m, 6²8'30.3"S, 74²'27.7"W, 17.ii.2009; (18) ZR de Sierra del Divisor, 411 m, 657'6"S, 7351'33"W, 15-16.iii.2009; (8) Sierra del Divisor, Qda. Betilia, 160 m, 6¹2'45.9"S, 73¹4'12.6"W, 05-06.iii.2009; (4) Sierra del Divisor, nr. Qda. Sábalo, 155 m, 6¹4'59.4"S, 74¹3'7.17"W, 3-4.ii.2009; (7) Sierra del Divisor, $181 \mathrm{~m}, 6^{\circ} 27^{\prime} 32.5^{\prime \prime S}, 7^{\circ} 0^{\prime} 14.39^{\prime \prime W}, 19-20$. ii.2009; (2) Sierra del Divisor, $5 \mathrm{~km}$ del río Campanagua, 160 m, 6¹9'30"S, 7346'9"W, 20-21.x.2008; (2) Sierra del Divisor, $1 \mathrm{~km}$ río Trompeteros, $175 \mathrm{~m}, 6^{\circ} 28^{\prime} 31.7^{\prime \prime S}$, 74²'30"W, 18-19.x.2008; (3) Sierra del Divisor, Qda. Punga, $159 \mathrm{~m}, 6^{\circ} 30^{\prime} 59.1^{\prime \prime S}, 74^{\circ} 1^{\prime} 20.47^{\prime \prime W}$, 21-23.ii.2009; (2) Zona Reservada Sierra del Divisor, 205 m, 6²1'59.21"S, 7327'53.40"W, 17-21.v.2013; (1) Zona Reservada Sierra del Divisor, $155 \mathrm{~m}, 6^{\circ} 20^{\prime} 19.86^{\prime S}, 7^{\circ} 42^{\prime} 46.82^{\prime \prime W}$, 30.iv.2013; (1) ZR de Sierra del Divisor, $211 \mathrm{~m}, 6^{\circ} 55^{\prime} 9^{\prime \prime S}$, 7350'47"W, 11 -13.iii.2009; (1) Tamshiyacu Fundo, 112 m, 357'30.35"S, 7301'40.45"W, 17-22.ii.2018 (1) Tamshiyacu Fundo, 116 m, 358'48.61"S, 73²'30.38"W, 17- 
22.ii.2018; (2) Punchana-Astoria, $103 \mathrm{~m}, 03^{\circ} 38^{\prime} 22^{\prime \prime S}$, 7313'15.4"W, 4.iii.2014; (1) Requena, 114 m, 5²1'40.5"S, 74¹9.28"W, 25-30.xi.2013; (2) Trompeteros, a $3 \mathrm{~km}$ de río Corrientes, $177 \mathrm{~m}, 3^{\circ} 16^{\prime} 30.4^{\prime \prime S}, 7^{\circ} 37^{\prime} 24.7^{\prime \prime} \mathrm{W}$, 28-29.xi.2008; (1) río Copalyacu, $161 \mathrm{~m}, 3^{\circ} 25^{\prime} 12^{\prime \prime S}$, 75¹5'36"W, 07-xi.2009; (1) Requena, nr. Florida, 120 m, 5²7'43.5"S, 74²'11"W, 26.v.2014; (1) Datem del Marañón, Santa Ana, Quebrada Copal, $132 \mathrm{~m}, 4^{\circ} 59^{\prime} 44.5^{\prime \prime}$, 76²1'25"W, 72.xi.2012; (1) Trompeteros, Pavayacu, 168 m, 3³1'55.02"S, 75²5'5.30"W, 26.viii.2018; (1) Maynas, margen del río Urituyacu, Urarinas, $150 \mathrm{~m}, 4^{\circ} 08^{\prime} 50.05^{\prime \prime S}$, 7600'54.93"W, 16.xi.2009; (3) Alto Amazonas, $190 \mathrm{~m}$, 5²7'7.8"S, 76²8'34"W, 1.x.2012; (8) Maynas, río Itaya, $128-159 \mathrm{~m}, 4^{\circ} 15^{\prime} 52.4^{\prime \prime S}, 73^{\circ} 47^{\prime} 18.3^{\prime \prime W}$; (6) Maynas, río Itaya, $121-139 \mathrm{~m}, 4^{\circ} 20^{\prime} 23.03^{\prime \prime S}, 73^{\circ} 49^{\prime} 42.48^{\prime \prime} \mathrm{W}$, 13.ii.2009; (1) Maynas, Napo, río Curacay, Gaseoducto Barret, $1^{\circ} 35^{\prime} 13.38 " \mathrm{~S}, 7^{\circ} 24^{\prime} 31.08^{\prime \prime W}, 16-18 . i i i .2008$; (2) Loreto, $201 \mathrm{~m}, 3^{\circ} 22^{\prime} 59.01^{\prime \prime S}, 7^{\circ} 22^{\prime} 41.37^{\prime \prime}$, iii.2018 (2) Maynas, Miraflores, $69 \mathrm{~m}, 3^{\circ} 47^{\prime} 4.8^{\prime \prime} \mathrm{S}, 73^{\circ} 41^{\prime} 43^{\prime \prime} \mathrm{W}$, 10.v.2012; (2) río Pucayacu, 90 m, 540'37.7"S, 73¹7'14.6"W, 15.ix.2012; (4) Albarenga north. Qda. Aguanegra, $135 \mathrm{~m}, 2^{\circ} 50^{\prime} 57^{\prime \prime S}, 74^{\circ} 58^{\prime} 45.4^{\prime \prime W}, 22 . i .2009$; (1) Datem del Marañón, Morona, 125 m, 359'33.6"S,
77²13'53.86"W, 24-26.iii.2014; (1) Iquitos, 4²1'35.48"S, 7309'43.21"W, 13.i.2006; (1) Centro de Investigación Genaro Herrera, 455'S, 7345'W, 25.x.1989; (1) Sarayacu, CCPP. Miguel Grau, 140m, 6³7'27.40"S, 75³'54.10"W, 7-3.xi.2013; (1) Urarinas, Nueva Esperanza, $125 \mathrm{~m}$, $3^{\circ} 9^{\prime} 40.34 " \mathrm{~S}, 75^{\circ} 43^{\circ} 32.06^{\prime W}$, 28.xi.2018; (1) Loreto, 114 m, 4³8'23.8"S, 76²18'0.1"W, 30.vi.12.

Comentario: esta especie presenta un rango altitudinal entre 30 y 1100 m de altitud, su distribución es amazónica, está registrada en Bolivia, Brasil, Colombia, Ecuador, Guyana Francesa, Surinam, Perú y Venezuela. En Perú ocurre en los departamentos Loreto, Ucayali, Madre de Dios (Génier 2009), en el MUSM se encontraron individuos de Amazonas. En el departamento de Loreto, la especie ha sido encontrada durante todo el año. Esta especie habita en varillares y en bosques de terraza media y baja. Puede ser colectada con trampas de cebo (Bait trap).

\section{Eurysternus gracilis Génier, 2009}

(Figs. 4a, 4b, 4c, Fig. 15).

Eurysternus gracilis Génier, 2009: 34.

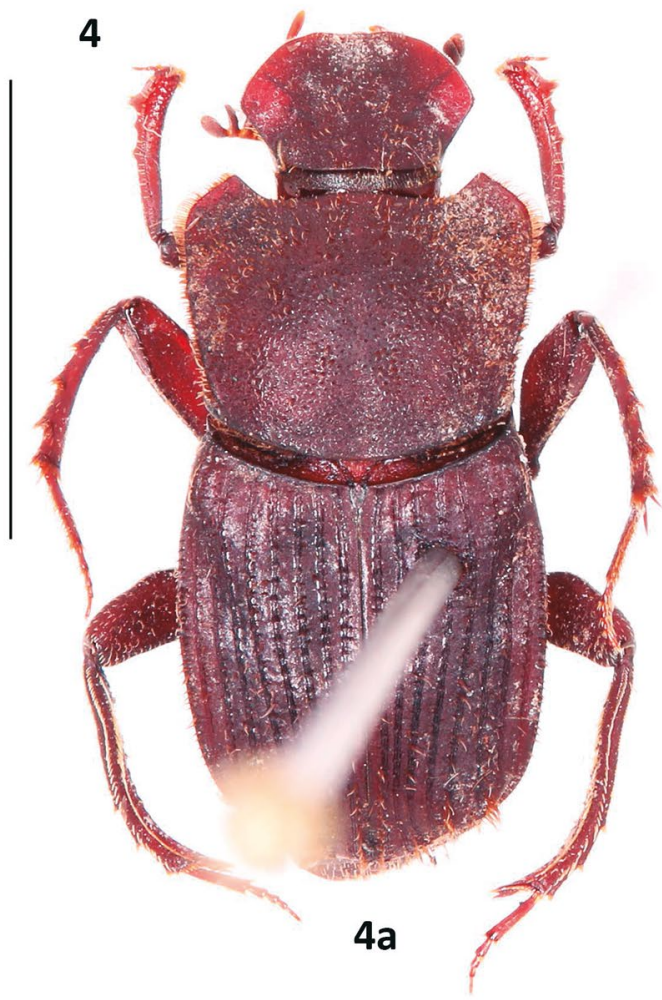

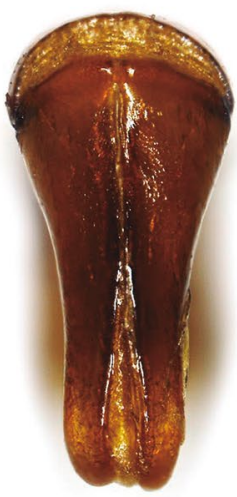

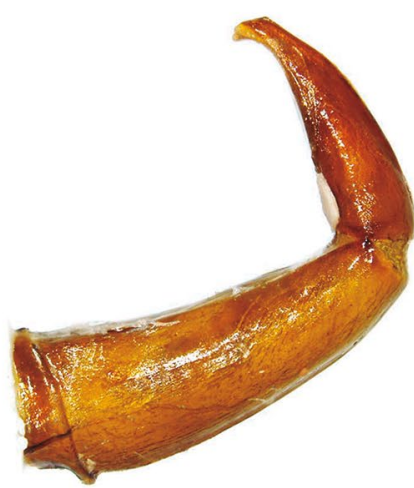

$4 b$
$4 c$

Figura 4. Eurysternus gracilis Génier. 4a) Habitus dorsal del macho. 4b) Aedeagus vista frontal. 4c) Vista lateral. Barra de escala: $5 \mathrm{~mm}$.

Diagnosis: largo: 7.5 - $10 \mathrm{~mm}$, ancho: $3.4-4.5 \mathrm{~mm}$. Coloración similar a la E. cayennensis. Cabeza con puntaciones oceladas pequeñas moderadamente densas, setas concentradas en la frente, margen posterior de la cabeza con 2 mechones de sedas; margen anterior del clípeo en machos simple y curvado hacia abajo, en hembras con 2 dientes en el margen. Pronoto con puntuación ocelada densa, mayor y más confluente en el centro, base y esqui- nas anteriores, sedas largas entremezcladas con sedas cortas y anchas (escamosas) insertadas en el centro de las puntuaciones; ángulos anteriores rectos; lóbulo central del metasterno cubierto por puntuaciones oceladas. Élitros con microescultura formando una red de líneas casi transversales, interestrías cubiertas con sedas cortas erectas, entremezcladas con algunas sedas largas y curvadas, ápice de la tercera interestría con un mechón 
de sedas, y callo apical de la quinta y séptima interestría con una hilera de sedas alargadas. Carena medio ventral del profémur lustrosa, que no alcanza a sobrepasar los $3 / 4$, margen anterior del fémur carenado, en algunos machos con un diente, protibias poco curvadas con aproximadamente 10 tubérculos en su borde interno, borde externo con tres dientes pequeños, siendo el apical el más desarrollado, protibias de las hembras simples, con tres dientes desarrollados en el borde externo; metacoxas unicolores, metafémur sin dientes o tubérculos, metatibias algo sinuosas, cara interna sin fila de tubérculos, a lo mucho se nota leves granulaciones, borde externo con una carena fuerte y lustrosa, ápice de las tibias con una espina corta articulada. Aedeagus ver Fig. 4b y Fig. $4 c$.

Material examinado: 23 especímenes examinados, 12 machos y 11 hembras.

PERÚ: Loreto: (4) Requena, $109 \mathrm{~m}, 5^{\circ} 28^{\prime} 31.4 " \mathrm{~S}$, 74²1'55.8"W, 18-23.xi.2013; (2) Requena, $114 \mathrm{~m}$, 521'40.5"S, 74¹9'28"W, 25-30. xi.2013; (1) Requena, Puinahua, Bretaña, $64 \mathrm{~m}, 5^{\circ} 19^{\prime} 12.9^{\prime \prime S}, 7^{\circ} 16^{\prime} 36^{\prime \prime} \mathrm{W}$, 21-22.v.2014; (1) Requena, Puinahua, Bretaña, 119 m, 5¹4'49"S, 74¹4'1.49"W, 21-22.v.2014; (1) Requena, Puinahua, Ancash, $113 \mathrm{~m}, 5^{\circ} 20^{\prime} 8.3^{\prime \prime S}, 74^{\circ} 16^{\prime} 38^{\prime \prime} \mathrm{W}$, 06-17.v.2014; (1) Prov. Requena, nr. Florida, $120 \mathrm{~m}$ 527'34.5"S, 74²1'11"W, 26.v.2014; (1) Requena, Bretaña, Lote 95, $102 \mathrm{~m}, 5^{\circ} 14^{\prime} 42.48 " \mathrm{~S}, 7^{\circ} 19^{\prime} 40.55^{\prime \prime W}$, 4.viii.18; (1) Requena, Bretaña, Lote 95, $112 \mathrm{~m}$, 5¹4'52.16"S, 74¹9'47.48"W, 4.viii.2018; (4) Iquitos, 100 m, 5¹5'10.1"S, 74¹9'31.2"W; (2) Sarayacu, CCPP Miguel Grau, 136 m, 6³7'8.60"S, 75³'49.80"W, 1-8.i.2013; (2) río Ucayali, Nuevo Tarma, $110 \mathrm{~m}, 5^{\circ} 9^{\prime} 0.09 " \mathrm{~S}, 7^{\circ} 7^{\prime} 11.61^{\prime \prime}$, 10.viii.2018; (1) Santa Rosa de Siamba (Urarinas), $148 \mathrm{~m}$, 47'14.3"S, 75³2'29.4"W, 29.v.12; (1) Maynas, Qda. Pucacuro, 186-188 m, 02²8'52"S, 7458'48.7"W, 10.ii.09; (1) Loreto, 139 m, 4²18'4" S, 7549'3"W, 12.vii.12.

Comentario: Esta especie presenta un rango altitudinal entre 25 y 305 m de altitud (Génier 2009, Camero y Lobo 2012). Su distribución está registrada en la amazonia de Brasil, Colombia y Perú; en este último, ocurre en los departamentos Loreto y Madre de Dios (Génier 2009), y ha sido encontrada en enero, febrero, mayo, julio y agosto.

\section{Eurysternus vastiorum Martínez, 1988}

(Figs. 5a, 5b, 5c, Fig. 14)

Eurysternus (Eurysternus) vastiorum Martínez, 1988: 287.

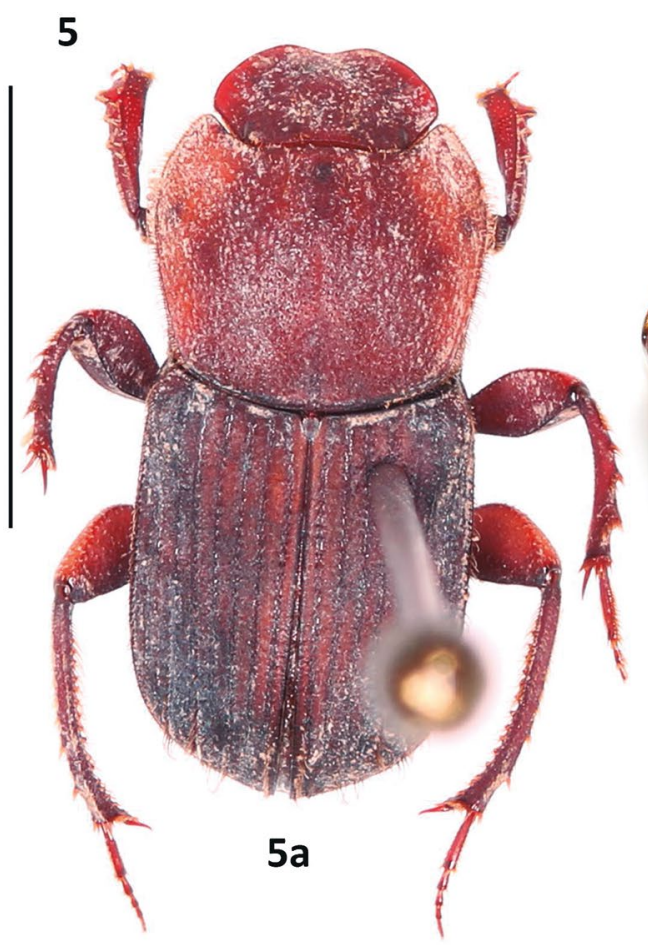

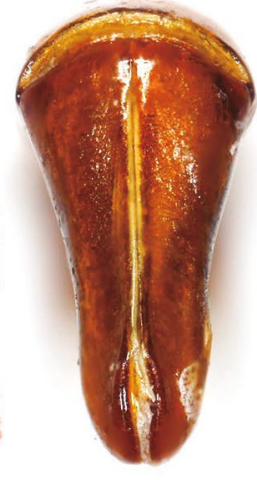

$5 b$

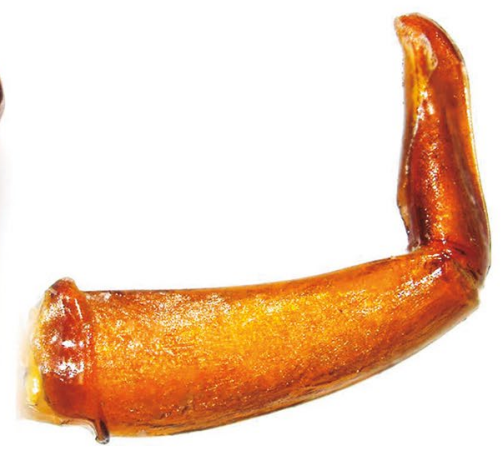

$5 c$

Figura 5. Eurysternus vastiorum Martínez. 5a) Habitus dorsal del macho. 5b) Aedeagus vista frontal. 5c) Vista lateral. Barra de escala: $5 \mathrm{~mm}$.

Diagnosis: largo: 8 - $10.5 \mathrm{~mm}$, ancho: $3-3.5 \mathrm{~mm}$. Coloración marrón rojiza a marrón oscura, en los individuos más claros se puede notar ciertos reflejos verdosos. Cabeza con puntuación pequeña levemente ocelada, con sedas más concentradas en la frente, margen posterior de la cabeza con 2 mechones de sedas. Pronoto con puntuaciones grandes y oceladas, sedas insertadas en la región anterior de estas, además presenta una región centro apical pequeña sin sedas ni puntuaciones, márgenes laterales del pronoto redondeados; metasterno con puntuación pequeña e irregular. Élitros con microescultura alveolada, interestrías cubiertas con sedas erectas 
cortas, ápice de la primera interestría con una hilera corta de seda largas, ápice de la tercera interestría con un mechón de setas y callo apical de la quinta y séptima interestría con una hilera de setas largas. Carena medio ventral del fémur anterior generalmente llega a la mitad, margen anterior carenado, en algunos machos con un diente. protibias rectas, borde interno ligeramente crenulado, sin tubérculos, borde externo con 3 dientes, en algunos machos los dientes medio y basal pueden estar algo reducidos, hembras con 3 dientes desarrollados; metacoxas oscuras con una franja de color claro, metafémur con una hilera de sedas más alargadas en el centro sobre la carena posterior, en hembras es simple, metatibias rectas, borde externo con una carena ventrolateral fuerte y lustrosa, borde interno con una fila de tubérculos, ápice de la tibia posterior con una espina larga y móvil. Aedeagus ver la Fig. 5b y Fig. 5c.

Material examinado: 19 especímenes examinados, 5 machos y 14 hembras.

PERÚ: Loreto: (2) Maynas, margen del río Urituyacu, Urarinas, $150 \mathrm{~m}, 4^{\circ} 08^{\prime} 50.05^{\prime \prime} \mathrm{S}, 7^{\circ} 00^{\prime} 54.93 " \mathrm{~W}, 16 . x \mathrm{i} .2009$; (1) Maynas, margen del río Urituyacu, Urarinas, $143 \mathrm{~m}$, $4^{\circ} 09^{\prime} 40.19^{\prime \prime S}, 76^{\circ} 00^{\prime} 40.92^{\prime \prime S}$, 18.xi.2009; (1) Requena, Bretaña, Lote 95, $112 \mathrm{~m}, 5^{\circ} 14^{\prime} 52.16^{\prime \prime S}, 7^{\circ} 19^{\prime} 47.46^{\prime \prime W}$, 4.viii.2018; (1) Requena, Bretaña, Lote 95, $114 \mathrm{~m}$, 514'56.48"S, 74¹9'33.00"W, 4.viii.2018; (1) Requena, 114 m, 5²1'40.5"S, 74¹9.28"W, 25-30.xi.2013; (2) Trompeteros, Pihuicho, $143 \mathrm{~m}, 3^{\circ} 48^{\prime} 30.79^{\prime \prime S}, 75^{\circ} 3^{\prime} 22.74^{\prime \prime W}$, 25.ix-9.x.2015; (2) Prov. Requena, nr. San Antonio, 103 m, 5³9'12.3"S, 74¹5'17"W, 29-30.v.2014; (1) río Urituyacu, Ayahuasca, $151 \mathrm{~m}, 4^{\circ} 06^{\prime} \mathrm{S}, 7^{\circ} 0^{\prime} 36^{\prime \prime W}, 19 . i i i .2010$; (1) Río Urituyacu, $144 \mathrm{~m}, 4^{\circ} 12^{\prime} 36^{\prime \prime S}, 75^{\circ} 29^{\prime} 24^{\prime \prime W}, 24 . i i i .2010$; (2) Iquitos, $100 \mathrm{~m}, 5^{\circ} 15^{\prime} 10.1^{\prime \prime S}, 7^{\circ} 19^{\prime} 31.2^{\prime \prime W}, 20-24$. vii.2012; (1) Maynas, Napo, río Curacay, Gaseoducto Barret, $1^{\circ} 35^{\prime} 13.38 " S, 7^{\circ} 24^{\prime} 31.08^{\prime \prime W}$, 16-18.iii.2008; (1) Camp. El Fuerte (Cerros de Orellana), 17.vii.1988; (2) Zona Reservada Sierra del Divisor, 205 m, 6²5'11.96"S, 7332'7.00"W, 23-26.v.2013; (1) Yurimaguas, $129 \mathrm{~m}$, 540'37.7"S, 76²17'14.6"W, 17.ix.2012.

Comentario: esta especie tiene un rango altitudinal entre 80 y 1650 m de altitud, su distribución está circunscrita a Bolivia, Brasil, Colombia, Ecuador, Perú y Surinam; en Perú ocurre en los departamentos Huánuco, Loreto, Madre de Dios y San Martin (Génier 2009); en el MUSM se encontraron individuos de Amazonas, Cusco y Ucayali. Ha sido registrada en los meses de marzo, mayo, julio, agosto, septiembre, octubre y noviembre. La especie puede ser colectada con trampas de caída o 'pitfall' y con trampas de bandeja amarilla, y habita en bosques de terraza baja.

\section{Eurysternus ventricosus Gill, 1990}

(Figs. 6a, 6b, 6c, Fig. 16).

Eurysternus ventricosus Gill, 1990: 358.
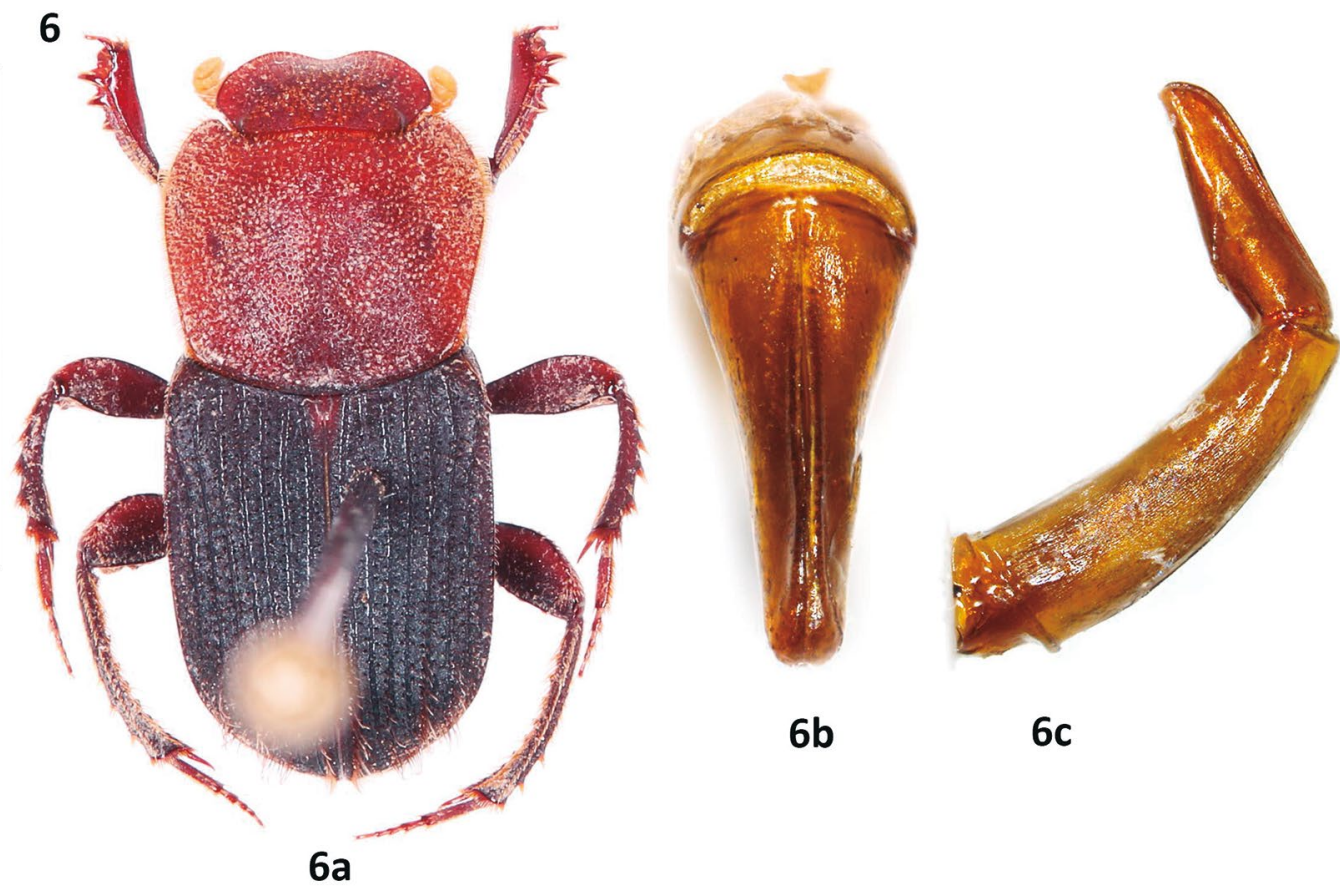

$6 c$

Figura 6. Eurysternus ventricosus Gill. 6a) Hábitus dorsal del macho. 6b) Aedeagus vista frontal. 6c) Vista lateral. Barra de escala: $5 \mathrm{~mm}$

Diagnosis: largo: 7.5 - $9 \mathrm{~mm}$, ancho: $2-3.5 \mathrm{~mm}$. Coloración rojiza oscurecida en la cabeza y pronoto, y marrón muy oscuro en los élitros. Cabeza con puntuaciones pequeñas, sedas cortas distribuidas casi regularmente. Pronoto con puntuaciones oceladas muy densas y uniforme- mente distribuidas, portando sedas cortas y engrosadas en la base (escamosas), ángulos anteriores redondeados; lóbulo central del metasterno densamente punteado, puntuación pequeña no ocelada. Élitros con microescultura reticular entremezclada con unas líneas casi transversal, 
interestrías cubiertas por hileras de sedas cortas y erectas, región pre apical y apical de la primera interestría con una hilera de seda largas, ápice de la tercera interestría con un mechón de sedas, y callo apical de la quinta y séptima interestría con una hilera de sedas largas. Carena medio ventral de profémur lustroso, que alcanza más de la mitad del fémur, margen anterior carenado con pequeño diente en machos, protibias en machos algo rectas, borde interno con aproximadamente seis tubérculos, borde externo con tres dientes poco desarrollados, en hembras con los dientes más desarrollados, metacoxas oscuras, con una franja clara; metafémur sin hilera de sedas largas, metatibias ligeramente curvadas, cara interna con una fila de tubérculos, cara externa con la carena ventrolateral lustrosa, delgada; ápice de la tibia con la espina larga móvil. El quinto esternito abdominal del macho con un tubérculo. Aedeagus ver Fig. 6b y Fig. 6c.

Material examinado: 4 especímenes examinados, 1 macho y 3 hembras.

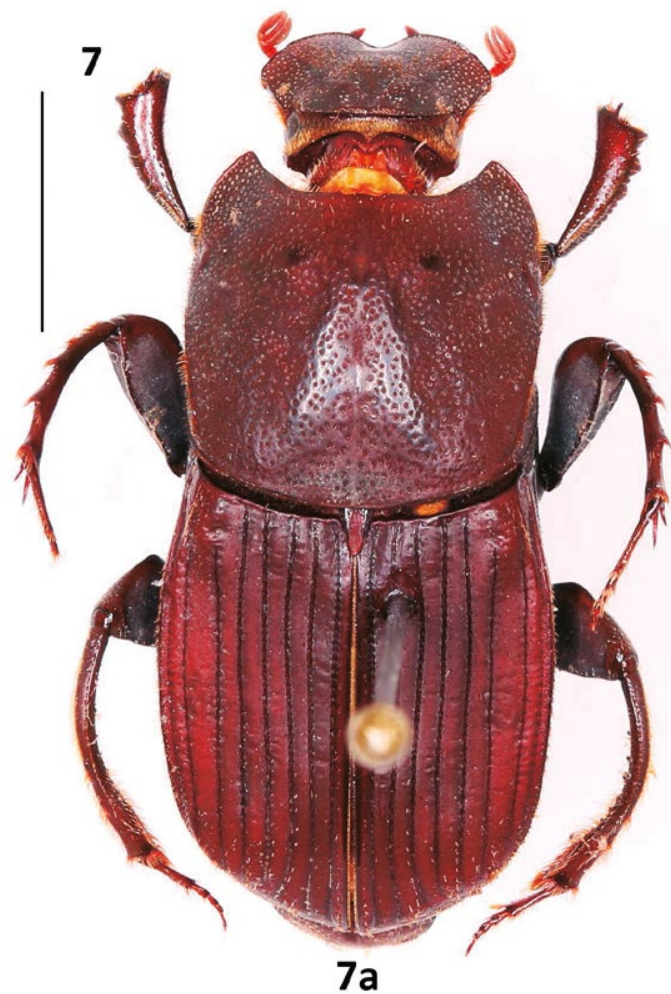

PERÚ: Loreto: (3) ZR de Sierra del Divisor, $411 \mathrm{~m}$, 657'6"S, 7351'33"W, 15-16.iii.2009; (1) Zona Reservada Sierra del Divisor, 155 m, 6²4'9.86"S, 7342'46.82"W, 30.iv.2013.

Comentario: esta especie presenta un rango altitudinal entre 30 a 1500 m de altitud, su distribución está registrada en la Amazonía de Bolivia, Brasil, Guyana, Guyana Francesa y Venezuela (Génier 2009), siendo un nuevo registro para Perú. En Loreto ha sido encontrada en marzo y abril.

\section{GRUPO FOEDUS}

Eurysternus foedus Guérin-Méneville, 1830

(Figs. 7a, 7b, 7c, Fig. 15)

Eurysternus foedus Guérin-Méneville, 1830: pl.21, fig.5.

Figura 7. Eurysternus foedus Guérin-Méneville. 7a) Habitus dorsal del macho. 7b) Aedeagus vista frontal. 7c) Vista lateral. Barra de escala: $5 \mathrm{~mm}$.

Diagnosis: largo: 15 - $19 \mathrm{~mm}$, ancho: $6.5-8.5 \mathrm{~mm}$. Coloración marrón rojiza a marrón oscuro, con ciertos reflejos verdosos. Cabeza con puntuaciones pequeñas y oceladas, mayores y confluentes en las genas. Pronoto con puntuación ocelada uniforme, superficie con 2 elevaciones divergentes a modo de ' $\mathrm{V}$ ', que son ligeramente más lustrosas con una depresión triangular posterior; lóbulo medio del metasterno con puntuaciones oceladas, puntuaciones más grandes cercanas a las coxas medias. Élitros con la quilla de la pseudoepipleura poco elevada, quinta interestría ligeramente más elevada que la quilla; ápices de la quinta y séptima interestría con mechones

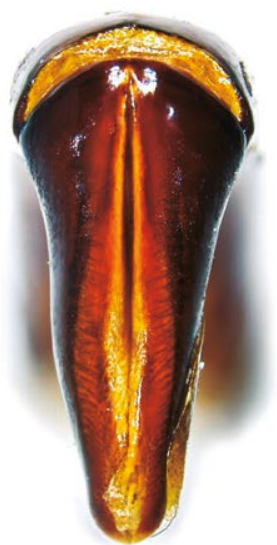

7b

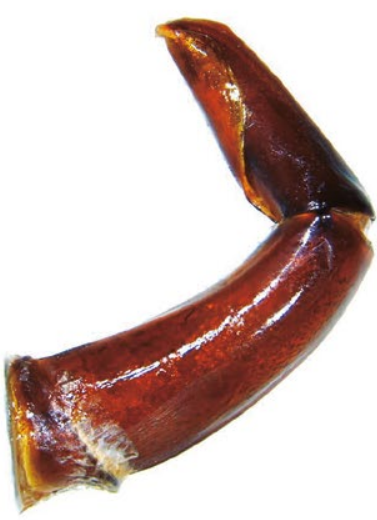

7c de setas cortas, poco notorias. Protibias anteriores en machos moderadamente curvadas, borde interno con numerosos tubérculos, y región ventral con una hilera longitudinal de tubérculos pequeños, en hembras el borde interno es más crenulado; borde externo con tres dientes poco desarrollados en machos y ligeramente más desarrollados en hembras, ápice de la tibia carente de protarso; profémur con un diente redondeado proximal en el margen posterior, en hembras más pequeño y menos definido, metatibias fuertemente curvadas en machos y sinuosas en hembras, ápice de la tibia con la espina fusionada. Aedeagus ver Fig. 7 b y Fig. 7 c. 
Material examinado: 22 especímenes examinados, 9 machos y 13 hembras.

PERÚ: Loreto: (3) Aguas Calientes (Contamana), 12.ix.1986; (2) Calientillo (Contamana), 150 m, 10.v.1985; (2) Datem del Río Marañón, 132 m, $4^{\circ} 59^{\prime} 44.5^{\prime \prime S}, 76^{\circ} 18^{\prime} 25^{\prime \prime} \mathrm{W}, 3 . v i i .2012$; (1) Yurimaguas, 129 m, 540'37.7"S, 76¹7'14.6"W, 14.v.2012; (3) Maynas, Marg. del río Urituyacu, Urarinas, $143 \mathrm{~m}, 4^{\circ} 09^{\prime} 40.19^{\prime \prime S}$, 7600'40.92"S, 18.xi.2009; (2) Sarayacu, CCPP Miguel Grau, 136 m, 6³7'8.60"S, 75³'49.80"W, 1-8.i.2013; (1) Sarayacu, CCPP Miguel Grau, 140 m, 6³7'27.40"S, 75³'54.10"W, 7-13.xi.2013; (3) Punchana-Astoria, 103 m, 0338'22"S, 7313'15.4"W, 4.iii.2014; (1) Iquitos, km 28 SO Iquitos, RN Allpahuayo Mishana, 148 m, 358'21.80"S, 73²5'29.12"W, 29-31.x.2010; (1) Iquitos, km 24.6 SO Iquitos, RN Allpahuayo Mishana, $137 \mathrm{~m}, 3^{\circ} 57^{\prime} 10.3^{\prime \prime S}$, 73²4'25.34"W, 29-31.x.2010; (1) Río Copalyacu, 161 m, $3^{\circ} 25^{\prime} 12^{\prime \prime S}, 75^{\circ} 15^{\prime} 36^{\prime \prime W}, 7-8 . x .2009$; (1) Requena, 114 m, $5^{\circ} 21^{\prime} 40.5^{\prime \prime S}, 74^{\circ} 19^{\prime} 28^{\prime \prime W}, 25-30 . x i .2013$.

Comentario: esta especie presenta un rango altitudinal entre 0 y $3000 \mathrm{~m}$ de altitud, con distribución desde el sur de México hasta Bolivia; en Perú ocurre en los departamentos Amazonas, Huánuco, Loreto, Madre de Dios y Pasco (Génier 2009), en el MUSM se encontraron especímenes de Cusco, Junín, San Martin y Ucayali. En Loreto, la especie ha sido encontrada todo el año.

\section{GRUPO VELUTINUS}

\section{Eurysternus hypocrita Balthasar, 1939}

(Figs. 8a, 8b, 8c, Fig. 16)

Eurysternus hypocrita Balthasar, 1939: 114

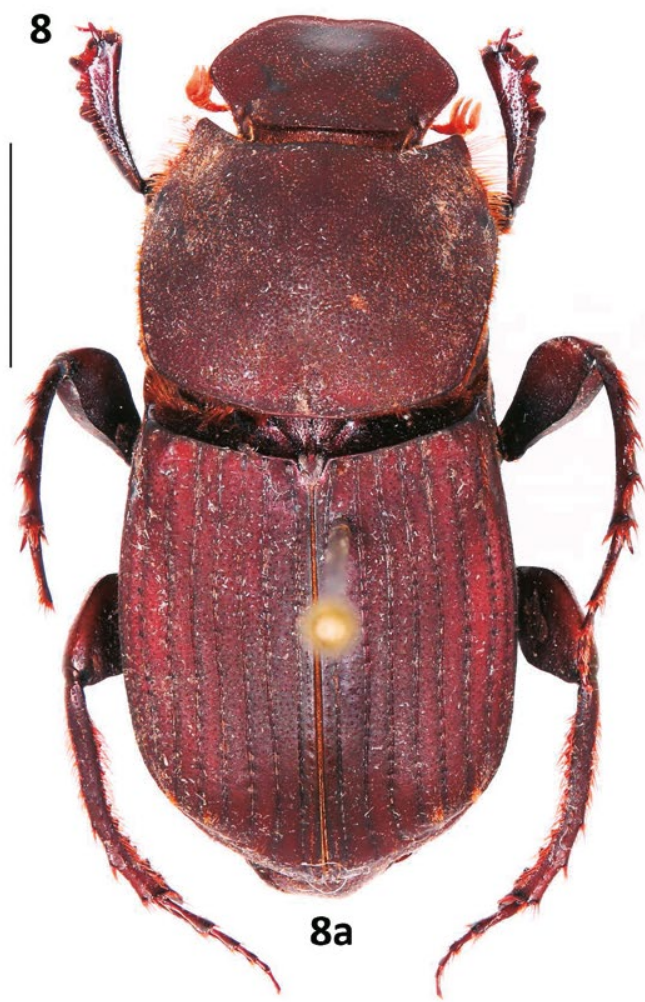

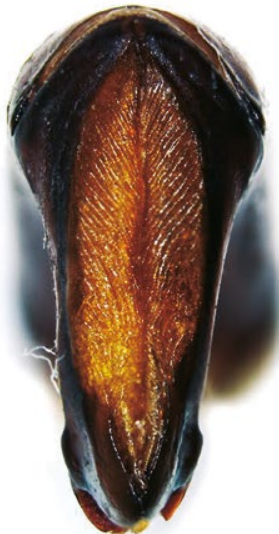

8b

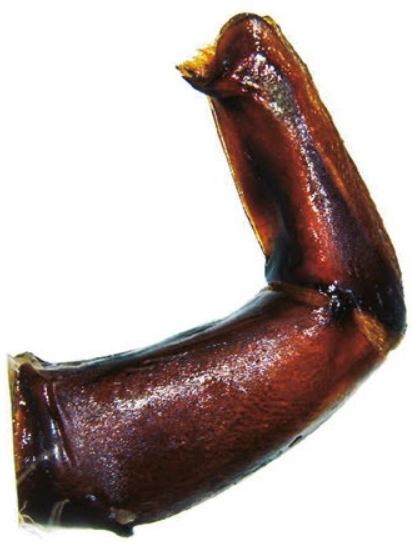

$8 c$

Figura 8. Eurysternus hypocrita Balthasar. 8a) Habitus dorsal del macho. 8b) Aedeagus vista frontal. 8c) Vista lateral. Barra de escala: $5 \mathrm{~mm}$.

Diagnosis: largo: 17.5 - $21 \mathrm{~mm}$, ancho: $7.5-8.5 \mathrm{~mm}$. Coloración marrón rojiza a marrón oscuro con reflejos verdosos. Cabeza con puntuaciones oceladas en la frente y genas, clípeo con puntuaciones oceladas pequeñas a finas. Pronoto con puntuaciones oceladas muy densas y confluentes, región apical con una leve banda longitudinal delgada, sin puntuaciones, a veces algo difusa en el centro del pronoto, ángulos anteriores sinuosos; lóbulo central del metasterno deprimido, con dos leves concavidades cercanas a la base, puntuaciones finas y escasas, los lados con puntuaciones más densas. Élitros con microescultura alveolada, sedas diminutas insertadas en las interestrías, ápice de la quinta y séptima interestrías con mechones de sedas muy cortas. Margen anterior del profémur con denticulaciones pequeñas, tprotibias algo curvadas, borde interno crenulado, cara ventral con un tubérculo proximal. Borde externo con tres dientes, más desarrollados en hembras; profémur del macho con una hilera de sedas cortas en la cara posterior, hembras sin hilera de sedas, metatibias levemente sinuosas en machos, borde interno con una fila de dientes, ápice con la espina fusionada en machos. Aedeagus ver Fig. 8b y Fig. 8c.

Material examinado: 48 especímenes examinados, 20 machos y 28 hembras. 
PERÚ: Loreto: (8) Maynas, alto río Pintayacu, $154 \mathrm{~m}$, 0240'24.8"S, 7441'25.1"W, 14.ii.2009; (1) Maynas, Qda Aguablanca, 160-177 m, 0255'16.3"S, 74²4'0.1"W

; (1) Maynas, Qda Aguablanca, $168 \mathrm{~m}, 2^{\circ} 55^{\prime} 12.18^{\prime \prime}$, 7449'00.16"W, 9.i.2009; (5) Maynas, Napo, río Curacay, Gaseoducto Barret, $1^{\circ} 35^{\prime} 13.38^{\prime \prime S}, 75^{\circ} 24^{\prime} 31.08^{\prime \prime W}$ 16-18.iii.2008; (1) Maynas, Napo, río Curacay, Gaseoducto Barret, $162 \mathrm{~m}, 1^{\circ} 34^{\prime} 38.15^{\prime \prime S}, 75^{\circ} 24^{\prime} 50.69 " \mathrm{~W}, 28$ 29.iii.2008; (1) Maynas, Río Itaya, 114-140 m 04¹5'48"S, 7346'39.6"W; (1) Maynas, Miraflores, 69 m, 347'4.8"S, 7341'43"W, 10.v.2012; (3) Río Copalyacu, $161 \mathrm{~m}, 3^{\circ} 25^{\prime} 33.24 " \mathrm{~S}, 75^{\circ} 15^{\prime} 36^{\prime \prime W}, 7-8 . x .2009$; (1) Maynas, río Copalyacu, Trompeteros, 120 m, 346'33.85"S, 75²5'30.93"W, 09.xii.2009; (2) Sierra del Divisor, 1 km Río Trompeteros, 175 m, 6²8'31.7"S, 74²'30"W, 18-19.x.2008; (1) Alto Amazonas, 212 m, 5²6'19.8"S, 73¹8'35"W, 06.vi.2012; (1) río Ungumayo, $171 \mathrm{~m}$, 408'08.16"S, 76²1'03.48"W, 29-30.xi.2009; (1) río Urituyacu, Ayahuasca, $151 \mathrm{~m}, 4^{\circ} 06^{\prime} \mathrm{S}, 76^{\circ} 0^{\prime} 36^{\prime \prime} \mathrm{W}, 19$. iii.2010; (1) Loreto, $114 \mathrm{~m}, 4^{\circ} 38^{\prime} 23.8^{\prime \prime S}, 76^{\circ} 18^{\prime} 01^{\prime \prime W}$, 30.vi.2012; (1) El Indio (Cerros de Contamana), 18.ix.1986; (3) Calientillo (Contamana), 150m, 10.v.1985; (1) Urarinas, Nueva Esperanza, 212m, 3¹2'5.46"S, 75²4'40.48"W, 30.xi.2018; (1) Sierra del Divisor, río Campanagua, 149 m, 6¹9'30"S, 73³7'6"W, 27.x.2008; (1) Sierra del Divisor, $5 \mathrm{~km}$ del Río Campanagua, $160 \mathrm{~m}, 6^{\circ} 19^{\prime} 30^{\prime S}$,
7346'9"W, 20-21.x.2008; (1) Sierra del Divisor, cerca del Río Punga, $222 \mathrm{~m}, 6^{\circ} 55^{\prime} 11.2^{\prime \prime S}, 73^{\circ} 50^{\prime} 47^{\prime \prime W}$, 22-24.x.2008; (1) Sierra del Divisor, 2 km río Hubuya, 196 m, 659'31.8"S, 7359'26.07"W, 13-14.x.2008; (1) Zona Reservada Sierra del Divisor, $155 \mathrm{~m}, 6^{\circ} 24^{\prime} 9.86^{\prime \prime} \mathrm{S}$, 7342'46.82"W, 30.iv.2013; (7) Iquitos, km 24.6 SO Iquitos, RN Allpahuayo, Mishana, $137 \mathrm{~m}, 3^{\circ} 57^{\prime} 10.3^{\prime \prime S}$, 73²4'25.34"W, 29-31.x.2010; (3) Iquitos, km 28 SO Iquitos, RN Allpahuayo, Mishana, 148 m, 358'21.80"S, 7325'29.12"W, 29-31.x.2010.

Comentario: esta especie presenta un rango altitudinal entre 30 y 1000 m de altitud, con distribución en Bolivia, Brasil, Colombia, Ecuador, Guyana, Guyana Francesa, Perú, Surinam y Venezuela; en Perú ocurre en los departamentos Cusco, Junín, Loreto, Madre de Dios, San Martin y Ucayali, (Génier 2009), en MUSM se hallaron especímenes de Amazonas y Pasco. En Loreto, la especie ha sido encontrada todo el año. Se colectó usando trampas con cebo (bait trap).

\section{GRUPO HIRTELLUS}

Eurysternus lanuginosus Génier, 2009

(Figs. 9a, 9b, 9c, Fig. 14)

Eurysternus lanuginosus Génier, 2009: 70.
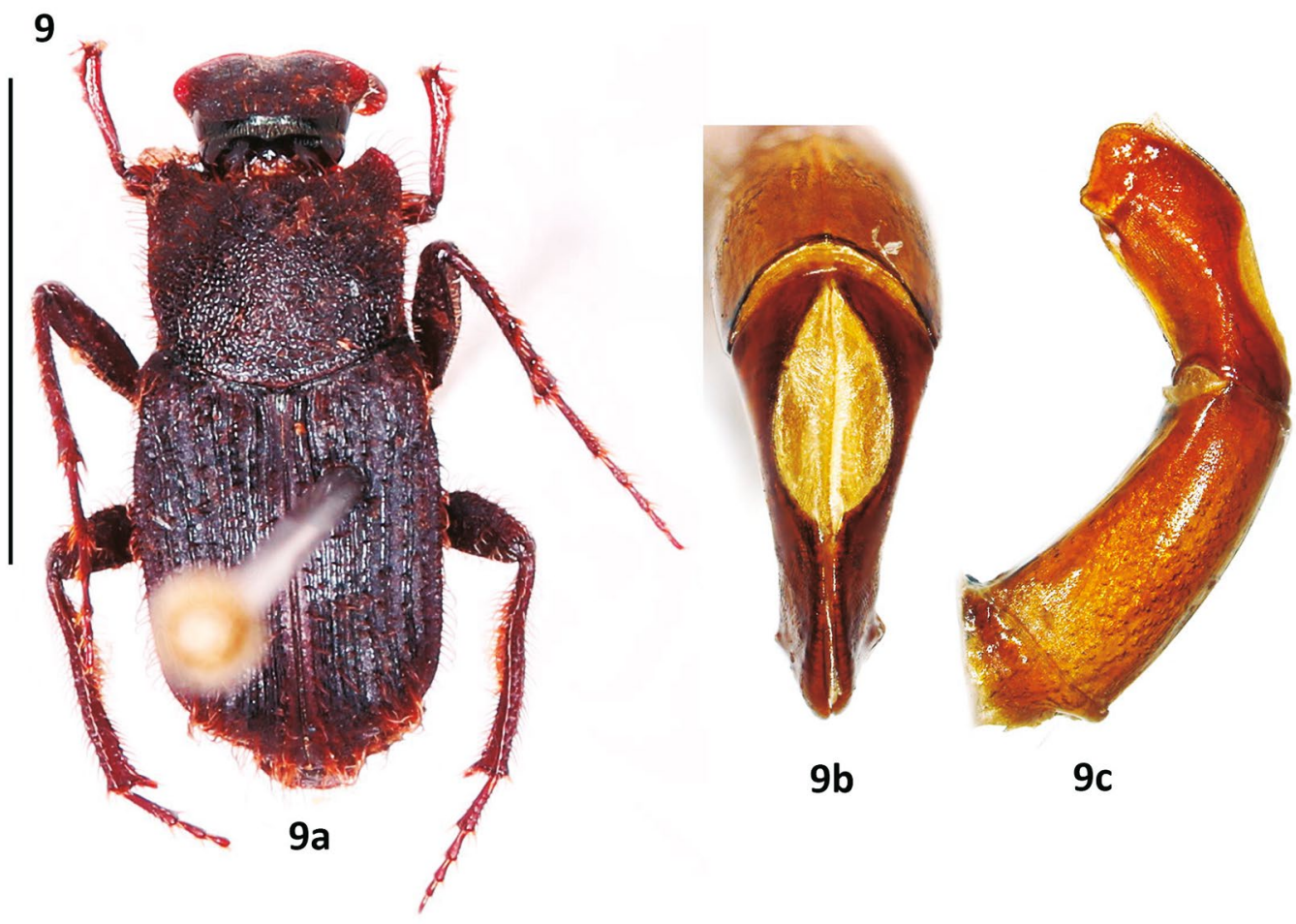

Figura 9. Eurysternus lanuginosus Génier. 9a) Habitus dorsal del macho. 9b) Aedeagus vista frontal. 9c) Vista lateral. Barra de escala: $5 \mathrm{~mm}$.

Diagnosis: largo: $6.5-8 \mathrm{~mm}$, ancho: $2.5-3.5 \mathrm{~mm}$. Coloración marrón oscura, cabeza con puntuación ocelada, mayor y más confluente en la región posterior, con setas insertadas casi en la región central de los puntos. Pronoto con puntuación ocelada muy confluente y den- sa, setas largas ligeramente recurvadas, en algunos casos están curvadas, insertadas en la región anterior de los puntos, algunos puntos con setas más cortas, microescultura formando una red de líneas casi transversales, márgenes laterales paralelos, ángulos anteriores lige- 
ramente redondeados a subtruncados diagonalmente, hembras con un diente apical; carenas proepisternales fusionadas antes de la mitad posterior, lóbulo central del metasterno con grandes puntos ocelados, similares al pronoto pero menos confluentes. Élitros con interestrías cubiertas con sedas similares a las del pronoto, callo apical de la quinta y séptima interestría con un mechón de sedas largas, ápice de la tercera interestría con un mechón de sedas. Protibias ligeramente sinuosas, con la región apical curvada, borde externo con aparentemente dos dientes, en algunos casos puede ser uno, en hembras con tres dientes situados casi en la región apical; metatibias en machos levemente sinuosas, cara externa con una carena lustrosa, cara interna con un cepillo de sedas finas conspicua, en hembras sin hilera de sedas, ápice de la tibia con la espina fusionada en machos. Último esternito abdominal cubierto de grandes puntos ocelados con sedas delgadas. Aedeagus ver Fig. 9b y Fig. 9c.

Los especímenes de Loreto presentan sedas largas recurvadas en el pronoto y élitros, Génier (2009) señala que E. lanuginosus tiene mucha variación intraespecifica, y estos caracteres pueden estar sujetos a la localidad o altitud; sin embargo, no se hace referencia a una variación para dichas sedas, las cuales menciona son rectas. En el MUSM revisamos especímenes de otras localidades, y se compararon con los paratipos y se hallaron individuos con 1) sedas curvadas, otros con 2) sedas ligeramente curvadas con algunas rectas y otros con 3) sedas completamente rectas; además, las 3 formas estaba en simpatría, por lo que este se consideraría otro carácter variante dentro de esta especie.

Material examinado: 3 especímenes examinados, 2 machos y 1 hembra.

PERÚ: Loreto: (2) Loreto: Río Urituyacu, $144 \mathrm{~m}$, 4²1'36"S, 75²9'24"W, 24.iii.2010; (1) río Urituyacu, Ayahuasca, $151 \mathrm{~m}, 4^{\circ} 06^{\prime} \mathrm{S}, 7^{\circ} 0^{\prime} 36^{\prime \prime} \mathrm{W}, 19 . \mathrm{iii} .2010$.

Comentario: esta especie presenta un rango altitudinal entre 150 y 1900 m de altitud, con distribución en Bolivia, Brasil, Colombia, Ecuador y Perú; en este último ocurre en los departamentos Amazonas, Cusco, Junín, Loreto y Madre de Dios (Génier 2009), además de estos, en el MUSM se encontraron individuos de Huánuco, Pasco y San Martin. Solo han sido registrados especímenes en febrero.

\section{Eurysternus squamosus Génier, 2009}

(Figs. 10a, 10b, 10c, Fig. 16).

Eurysternus squamosus Génier, 2009: 67.

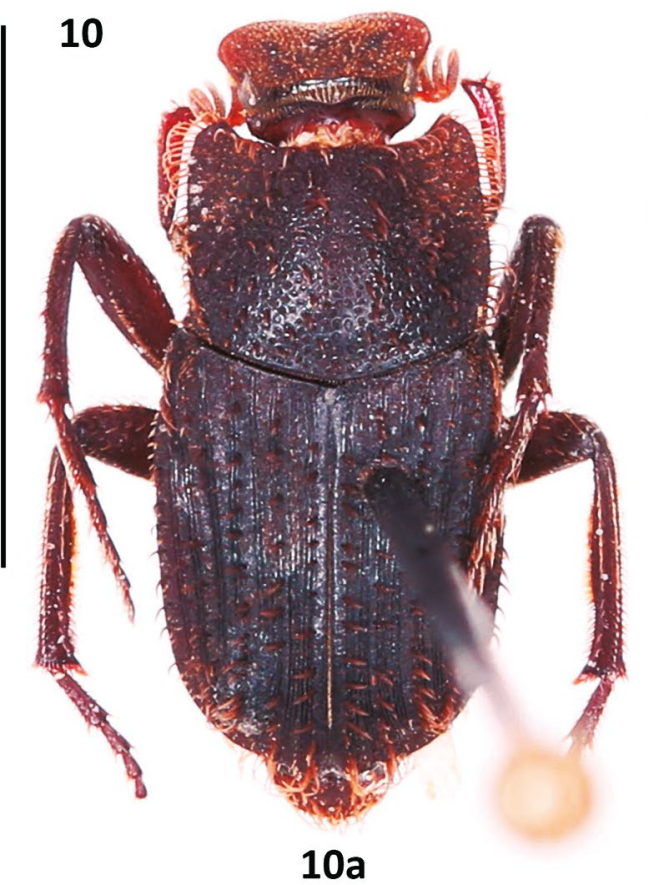

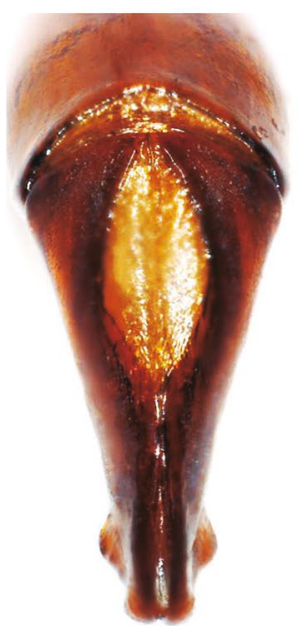

$10 \mathrm{~b}$

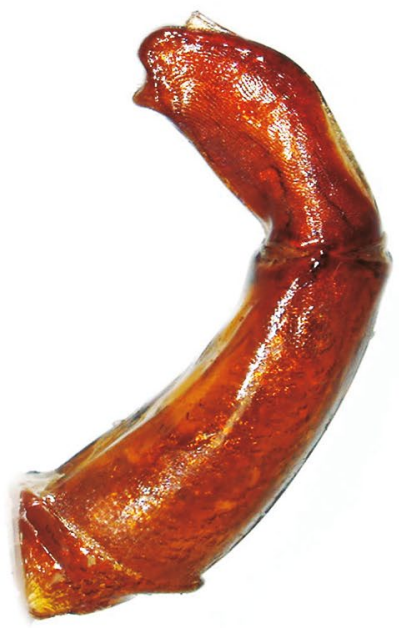

$10 c$

Figura 10. Eurysternus squamosus Génier. 10a) Hábitus dorsal del macho. 10b) Aedeagus vista frontal. 10c) Vista lateral. Barra de escala: $5 \mathrm{~mm}$.

Diagnosis: largo: 6.5 - $7.5 \mathrm{~mm}$, ancho: $2.5-3 \mathrm{~mm}$. Coloración similar a E. lanuginosus. Cabeza con puntuación ocelada, mayor y más confluente en la región posterior, con setas insertadas en la región central de los puntos. Pronoto con puntuación ocelada muy confluente y densa, sedas algo ensanchadas y curvadas insertadas en el centro de los puntos, algunos puntos con sedas cortas, microescultura formando una red de líneas casi transversal, márgenes laterales casi paralelos, carenas proepisternales fusionadas en la mitad, metasterno con grandes puntos ocelados similares al pronoto, pero menos confluentes. Élitros con interestrías cubiertas con filas de sedas curvadas, callo apical de la quinta y séptima interestría con un mechón de sedas largas, ápice de la tercera interestría con un tubérculo agudo, con un mechón de sedas. con un mechón de sedas. Protibias rectas, 
con la región rectas, con la región apical curvada hacia abajo, borde externo con aparentemente dos dientes, moderadamente curvados hacia abajo, tibias de las hembras con tres dientes situados casi en la región apical; metatibias en machos levemente rectas, cara externa con una carena fina cubierta de sedas, cara interna con una hilera de sedas finas que se van haciendo gradualmente más gruesas, en hembras es recta y sin hilera de sedas finas, ápice de la tibia con la espina fusionada en machos. Último esternito abdominal densamente cubierto por escamas (ensanchadas). Parameros ver en Fig. 10b y Fig. 10c.

Material examinado: 20 especímenes examinados, 12 machos y 8 hembras.

PERÚ: Loreto: (4) Iquitos, km 28 SO Iquitos, RN Allpahuayo Mishana, $148 \mathrm{~m}, 3^{\circ} 58^{\prime} 21.80^{\prime \prime S}, 73^{\circ} 25^{\prime} 29.12^{\prime \prime W}$, 29-31.x.2010; (6) Iquitos, $\mathrm{km} 24.6$ SO Iquitos, RN Allpahuayo Mishana, $137 \mathrm{~m}, 3^{\circ} 57^{\prime} 10.3^{\prime \prime S}, 73^{\circ} 24^{\prime} 25.34^{\prime \prime}$, 29-31.x.2010; (3) Alto Amazonas, $190 \mathrm{~m}, 5^{\circ} 27^{\prime} 7.8^{\prime \prime} \mathrm{S}$, 76¹8'34"W, 01.x.2012; (1) Loreto, 207 m, 3²2'57.10"S,
75²3'13.06"W, iii.2018; (1) Loreto, 151 m, 3³1'1.76"S, 75²5'38.98"W, iii.2018; (1) Santa Rosa de Siamba (Urarinas), $148 \mathrm{~m}, 4^{\circ} 7^{\prime} 14.3^{\prime \prime S}, 7^{\circ} 32^{\prime} 29.4^{\prime \prime} \mathrm{W}, 29 . v .2012$; (2) Maynas, Miraflores, $69 \mathrm{~m}, 3^{\circ} 47^{\prime} 4.8^{\prime \prime} \mathrm{S}, 73^{\circ} 41^{\prime} 43^{\prime \prime} \mathrm{W}$, 10.v.2012; (1) Maynas, río Itaya, $121-139 \mathrm{~m}$, 4²0'23.03"S, 7349'42.48"W, 13.ii.2009; (1) Trompeteros, a $5 \mathrm{~km}$ del río Parayacu, $176 \mathrm{~m}, 3^{\circ} 15^{\prime} 5^{\prime \prime S}, 75^{\circ} 27^{\prime} 2^{\prime \prime W}$, 03-40.xii.2008.

Comentario: Esta especie presenta un rango altitudinal entre 100 y 1200 m de altitud (Génier 2009, Camero y Lobo 2012), registrada en Colombia, Ecuador y Perú; en este último ocurre únicamente en el departamento de Loreto (Génier 2009). Ha sido encontrado en febrero, marzo, octubre y diciembre. Esta especie puede ser colectada usando trampas de bandeja amarilla y trampas Malaise.

\section{Eurysternus strigilatus Génier, 2009}

(Figs. 11a, 11b, 11c, Fig. 16).

Eurysternus strigilatus Génier, 2009: 74.

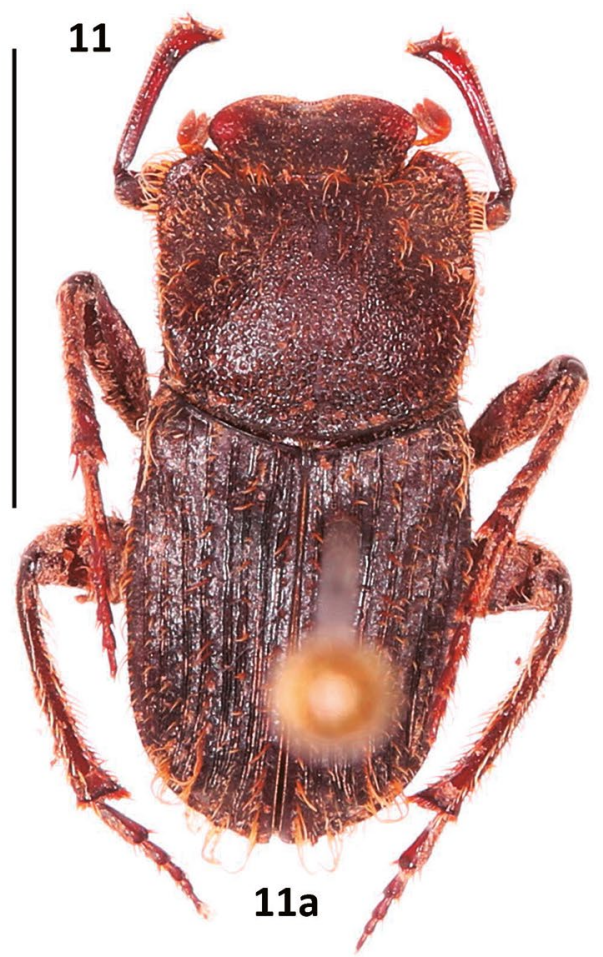

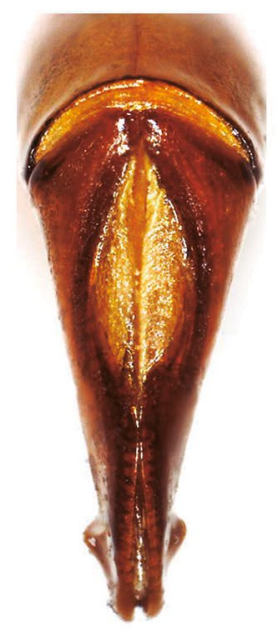

11b

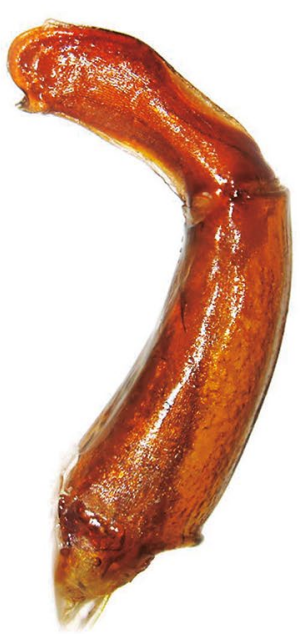

11c

Figura 11. Eurysternus strigilatus Génier. 11a) Habitus dorsal del macho. 11b) Aedeagus vista frontal. 11c) Vista lateral. Barra de escala: $5 \mathrm{~mm}$.

Diagnosis: largo: 6.5 - $9 \mathrm{~mm}$, ancho: $3-4 \mathrm{~mm}$. Coloración marrón rojiza a marrón oscura. Cabeza con puntuación ocelada, mayor y más confluencia en la región posterior, con setas insertadas en la región central de los puntos. Pronoto con puntuación ocelada muy confluente y densa, sedas largas escamosas y curvadas insertadas en el centro de los puntos, algunos puntos con setas más cortas, microescultura formando una red de líneas casi transversal, márgenes laterales ligeramente recurvados, carenas proepisternales no fusionadas, unidas solo en la base, metasterno con grandes puntos ocelados similares al pronoto, pero menos confluentes. Élitros con interes- trías cubiertas con filas de sedas curvadas, callo apical de la quinta y séptima interestría con un mechón de sedas largas, ápice de la tercera interestría con un tubérculo agudo, portando un mechón de sedas. Protibias rectas, con la región apical fuertemente curvada hacia abajo, borde externo con tres dientes fuertemente curvados hacia abajo, tibias de las hembras con tres dientes situados casi en la región apical; metatibias en machos levemente curvadas, cara externa con una carena fuerte y lustrosa, cara interna simple, en hembras es recta y simple, ápice de la tibia con la espina fusionada en machos. Último esternito abdominal cubierto de grandes puntos ocelados 
con sedas delgadas. Aedeagus ver Fig. 11b y Fig. 11c.

Material examinado: 44 especímenes examinados, 25 machos y 19 hembras.

PERÚ: Loreto: (4) ZR de Sierra del Divisor, $211 \mathrm{~m}$, 655'9"S, 7350'47"W, 11 -13.iii.2009; (4) ZR de Sierra del Divisor, Qda. Ubuya, 202m, 657'19"S, 74²'24"W, 28.ii-03.iii.2009; (3) ZR Sierra del Divisor, Qda. Ubuya, 197m, 659'47"S, 7358'42"W, 05-08.iii.2009; (3) Zona Reservada Sierra del Divisor, 213 m, 74'1"S, 74¹'21"W, 16-19.ii.2019; (1) Zona Reservada Sierra del Divisor, nr. Trapiche, 213 m, 70 $4^{\prime} 1$ "S, 74²1'21"W, 16-19.ii.2019; (1) Sierra del Divisor, cerca de Sarayacu, 195 m, 657'21.06"S, 74¹'27.4"W, 10-11.x.2008; (1) ZR de Sierra del Divisor, 314 m, 656'57"S, 7351'16"W, 14-18.iii.2009; (3) Sierra del Divisor, Qda. Punga, 145 m, 6²7'39.9"S, 740'59"W, 18-20.ii.2009; (1) Sierra del Divisor, Qda. Punga, 159 m, 6³0'59.1"S, 74²'20.47"W, 21-23.ii.2009; (2) Sierra del Divisor, cerca del río Punga, $222 \mathrm{~m}, 6^{\circ} 55^{\prime} 11.2^{\prime \prime S}$, 7350'47"W, 22-24.x.2008; (3) río Urituyacu, $144 \mathrm{~m}$, 4¹2'36"S, 75²9'24"W, 24.iii.2010; (2) Maynas, margen del río Urituyacu, Urarinas, $150 \mathrm{~m}, 4^{\circ} 08^{\prime} 50.05^{\prime S}$, 7600'54.93"W, 16.xi.2009; (2) río Urituyacu, Ayahuasca, $110 \mathrm{~m}, 4^{\circ} 05^{\prime} 25^{\prime \prime S}, 76^{\circ} 0^{\prime} 36^{\prime \prime W}$, 22.iii.2010; (3) río Ungumayo, $171 \mathrm{~m}, 4^{\circ} 20^{\prime} 23.93 " \mathrm{~S}, 73^{\circ} 49^{\prime} 42.48 " \mathrm{~W}, 29 . x i .2009$; (2) río Urituyacu, CCNN San Juan de Abejaico, 150 m, 405'25"S, 760'36"W, 17.xi.2009; (1) Camp. Venado (Bajo Inahuaillo), 400 m, 14.vii.1988; (1) Alto Amazo- nas, $190 \mathrm{~m}, 5^{\circ} 27^{\prime} 7.8^{\prime \prime S}, 76^{\circ} 18^{\prime} 34^{\prime \prime} \mathrm{W}, 01 . x .2012$; (2) $\mathrm{Cu}$ raray, $247 \mathrm{~m}, 1^{\circ} 43^{\prime} 55.56^{\prime \prime} \mathrm{S}, 7^{\circ} 27^{\prime} 37.33^{\prime \prime W}, 30 . i i i .2013$; (1) Trompeteros, Pavayacu, $129 \mathrm{~m}, 3^{\circ} 31^{\prime} 0.60 " \mathrm{~S}$, 75²5'2.49"W, 09.xi.2018; (1) Trompeteros, A $5 \mathrm{~km}$ del río Parayacu, 176 m, 3¹5'5"S, 75²7'2"W, 03-40. xii.2008; (1) Tamshiyacu Fundo, 112 m, 0357'30.35"S, 7301'40.45"W, 17-22.ii.2018; (1) San Andrés (Boras), 89 m, 340'57.6"S, 73¹7'8.4"W, 17.xi.2012; (1) C.N. Morales Bermúdez, nr. Río Trapiche, $87 \mathrm{~m}, 6^{\circ} 0^{\prime} 55.07 " \mathrm{~S}$, 74²'59.95"W, 12.viii.2018.

Comentario: Esta especie presenta un rango altitudinal entre 100 y 300 m de altitud (Génier 2009, Camero y Lobo 2012). Su distribución está registrada en Brasil y Perú; en este último ocurre en los departamentos Loreto y Madre de Dios (Génier 2009), en el MUSM hallaron individuos de Cusco, Huánuco, Pasco y Ucayali. Ha sido encontrada en febrero, marzo, julio, agosto, octubre, noviembre y diciembre.

\section{GRUPO IMPRESSICOLLIS}

\section{Eurysternus plebejus Harold, 1880}

(Figs. 12a, 12b, 12c, Fig. 15).

Eurysternus plebejus Harold, 1880: 14

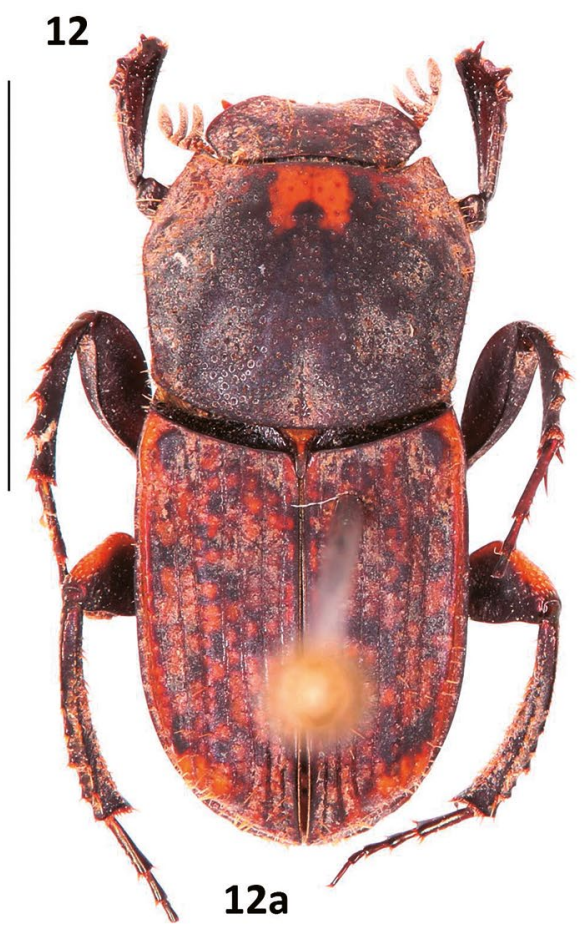

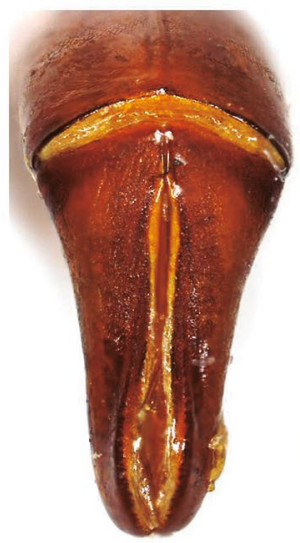

$12 b$

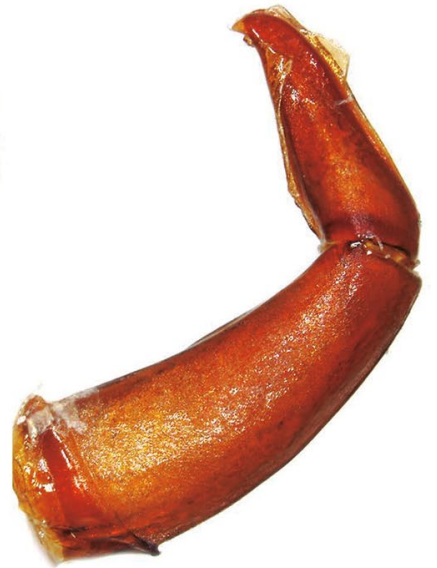

12c

Figura 12. Eurysternus plebejus Harold. 12a) Habitus dorsal del macho. 12b) Aedeagus vista frontal. 12c) Vista lateral. Barra de escala: $5 \mathrm{~mm}$.

Diagnosis: largo: 7 - $10.5 \mathrm{~mm}$, ancho: 3 - $4.5 \mathrm{~mm}$. Coloración marrón rojiza con manchas oscuras irregulares en la cabeza, región anterior con una pequeña mancha clara en forma de 'v', élitros color castaño anaranjado con patrones de manchas marrones irregulares, en algunos casos se puede notar reflejos metálicos verdosos; cara externa de las tibias posteriores color ligeramente más claro que los élitros, también con reflejos metálicos ver- 
dosos, en general la coloración puede estar más oscura. Cabeza con puntaciones oceladas poco densas y dispersas, con sedas insertadas en los puntos. Pronoto con puntuaciones oceladas, puntuaciones menos confluentes en la región centro apical, sedas erectas insertadas en los puntos; lóbulo central del metasterno con fuertes reflejos metálicos, región central con fóvea redondeada. Élitros con microescultura reticulada, sedas moderadamente cortas insertadas en las interestrías, carena humeral que se continua con la octava interestría, quilla de la pseudoepipleura baja, octava interesaría más elevada que la quilla, ápice de las primera, tercera y quinta interestrías con mechones de sedas algo cortas. Borde interno de la protibia con dos pequeños tubérculos proximales, borde posterior en tres dientes en la mitad anterior, las hembras con un pequeño diente agudo en la mitad posterior, en machos es poco notorio, metacoxas con dos franjas claras y oscuras intercaladas, metafémur de la hembra con un diente agudo proximal en el margen posterior, a veces esta reducido, machos sin diente; metatibias algo curvadas en machos, borde interno con una fila de tubérculos, ápice de la metatibia del macho con la espina fusionada. Aedeagus ver Fig. 12b y Fig. 12c.

Material examinado: 75 especímenes examinados, 53 machos y 22 hembras.

PERÚ: Loreto: (21) ZR de Sierra del Divisor, $211 \mathrm{~m}$, 655'9"S, 7350'47"W, 11 -13.iii.2009; (6) ZR Sierra del Divisor, Qda. Ubuya, 197 m, 659'47"S, 7358'42"W, 05-08. iii.2009; (24) ZR de Sierra del Divisor, 314 m, 656'57"S, 7351'16"W, 14-18.iii.2009; (4) ZR de Sierra del Divi- sor, Qda. Ubuya, 202 m, 657'19"S, 74²1'24"W, 28.ii-03. iii.2009; (2) Margen izquierda del río Ucayali, Contamana, $130 \mathrm{~m}, 7^{\circ} 27^{\prime} 49.42^{\prime \prime S}, 7^{\circ} 59^{\prime} 34.19^{\prime \prime W}$ 04-06.iv.2018; (5) Zona Reservada Sierra del Divisor, $213 \mathrm{~m}, 7^{\circ} 4^{\prime} 1 " \mathrm{~S}$, 74²'21"W, 16-19.ii.2019; (3) Zona Reservada Sierra del Divisor, nr. Trapiche, 213 m, 7²'1"S, 74²'21"W, 16-19. ii.2019; (2) ZR Sierra del Divisor, nr río Trapiche, $190 \mathrm{~m}$, 7³'22"S, 746'51"W, 20-22.ii.2009; (2) Datem del Río Marañón, $132 \mathrm{~m}, 4^{\circ} 59^{\prime} 44.5^{\prime \prime S}, 76^{\circ} 18^{\prime} 25^{\prime \prime W}$, 3.vii.2012; (2) Río Urituyacu, 144 m, 4²1'36"S, 75²9'24"W, 24.iii.2010; (1) Zona Reservada Sierra del Divisor, 172 m, 6³0'28.53"S, 73³7'29.15"W, 03-06.v.2013; (1) Sierra del Divisor, Qda. Punga, 185 m, 6²8'30.3"S, 74²'27.7"W, 17.ii.2009; (2) Sierra del Divisor, cerca de Sarayacu, 195m, 657'21.06"S, 74²'27.4"W, 10-11.x.2008.

Comentario: Esta especie presenta un rango altitudinal entre 5 y $2000 \mathrm{~m}$ de altitud, con amplia distribución desde Nicaragua hasta Bolivia; en Perú ocurre en los departamentos de Huánuco, Loreto, Madre de Dios (Génier 2009), en el MUSM se hallaron individuos de Amazonas, Cusco, Junín, Pasco, Puno, San Martin y Ucayali, siendo una de las especies de mayor distribución en el Perú. Se les encuentra durante todo el año.

\section{GRUPO INFLEXUS}

\section{Eurysternus wittmerorum Martínez, 1988}

(Figs. 13a, 13b, 13c, Fig. 14)

Eurysternus (Eurysternus) wittmerorum Martínez, 1988: 284.
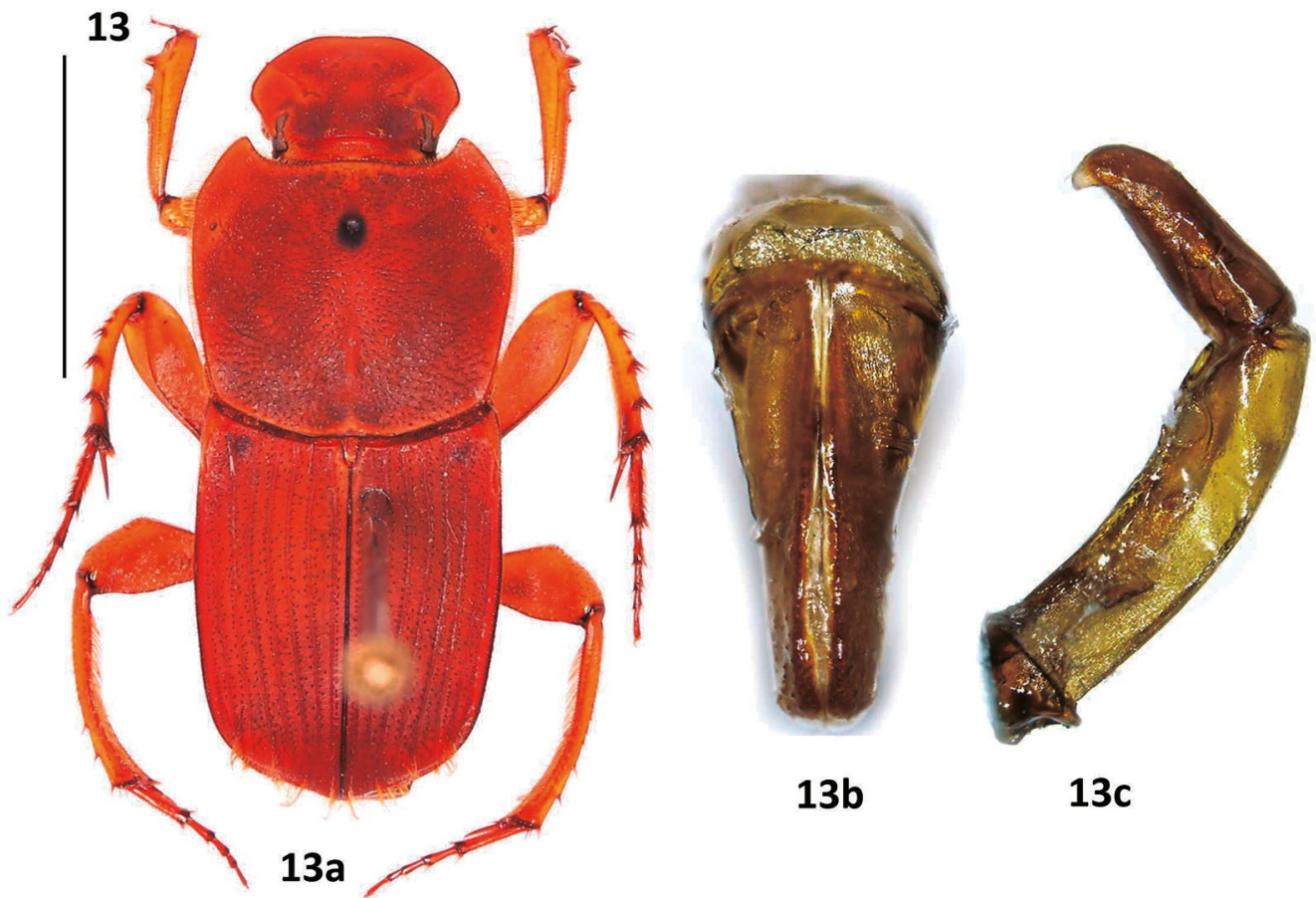

Figura 13. Eurysternus wittmerorum Martínez. 13a) Hábitus dorsal del macho. 13b) Aedeagus vista frontal. 13c) Vista lateral. Barra de escala: $5 \mathrm{~mm}$.

Diagnosis: largo: 9 - $12.5 \mathrm{~mm}$, ancho: $3.5-4.5 \mathrm{~mm}$. Coloración marrón anaranjada. Cabeza con puntuación pequeña no ocelada, región posterior con 2 mechones de sedas. Pronoto con puntuación ocelada levemente impresa y moderadamente densa, sedas cortas y curvadas insertas en las puntuaciones, además de una región cen- 
tral preapical ovalada pequeña moderadamente lustrosa sin puntuaciones; márgenes laterales ensanchados anteriormente, lóbulo central del metasterno con puntuación pequeña poco densa. Élitros con microescultura alveolada entremezclada con líneas reticulares casi transversales, interestrías cubiertas por sedas oscuras muy pequeñas, ápices de la primera, tercera, quita y séptima interestría con mechones de sedas largos y curvados. Margen anterior del profémur carenado, en los machos se forma un diente agudo y curvado, protibias en los machos rectas, borde interno crenulado, cara ventral con un tubérculo proximal, borde externo con tres dientes moderadamente curvados hacia abajo, en hembras únicamente con tres dientes, metacoxas claras, con una franja negra cerca de la base, metafémur con una carena posterior incompleta en hembras aparenta estar completa, metatibias ligeramente sinuosa en machos, recta en hembras, ápice de la tibia con una espina larga móvil. Primer esternito abdominal con un tubérculo carenado entre las coxas de los machos. Aedeagus ver en Fig. 13b y Fig. 13c.

Material examinado: 76 especímenes examinados, 32 machos y 44 hembras.

PERÚ: Loreto: (31) ZR de Sierra del Divisor, $211 \mathrm{~m}$, 655'9"S, 7350'47"W, 11 -13.iii.2009; (10) ZR de Sierra del Divisor, 314 m, 656'57"S, 7351'16"W, 14-18. iii.2009; (2) ZR de Sierra del Divisor, $411 \mathrm{~m}, 6^{\circ} 57^{\prime} 6 " \mathrm{~S}$, 7351'33"W, 15-16.iii.2009; (2) Zona Reservada Sierra del Divisor, 213 m, 74'1"S, 74²'21"W, 16-19.ii.2019; (2) Sierra del Divisor, Qda. Punga, 159 m, 6³0'59.1"S,

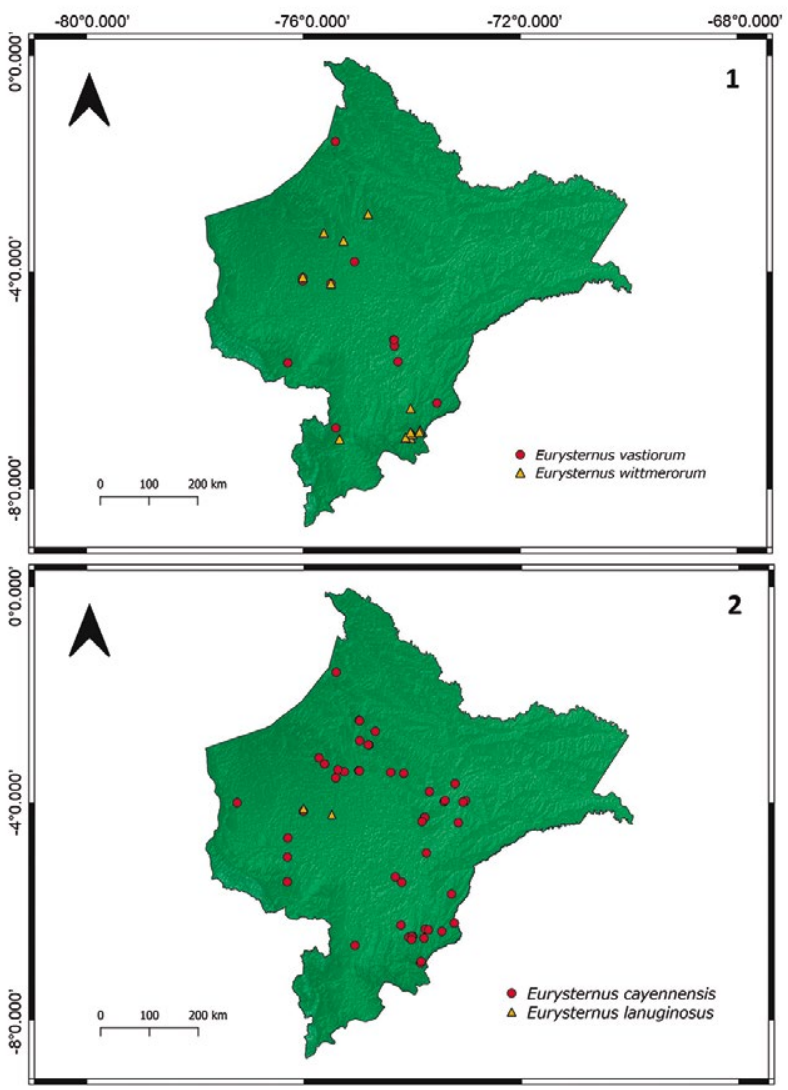

Figura 14. Mapa de distribución geográfica. 1) Eurysternus vastiorum y Eurysternus wittmerorum. 2) Eurysternus cayennensis y Eurysternus lanuginosus
74²'20.47"W, 21-23.ii.2009; (1) Sierra del Divisor, cerca del río Punga, $222 \mathrm{~m}, 6^{\circ} 55^{\prime} 11.2^{\prime \prime S}, 73^{\circ} 50^{\prime} 47^{\prime \prime}, 22-$ 24.x.2008; (10) ZR de Sierra del Divisor, Qda. Ubuya, 202 m, 657'19"S, 74¹'24"W, 28.ii-03.iii.2009; (3) ZR Sierra del Divisor, Qda. Ubuya, 197 m, 659'47"S, 7358'42"W, 05-08.iii.2009; (2) Zona Reservada Sierra del Divisor, 213 m, 74'1"S, 74²'21"W, 16-19.ii.2019; (2) ZR Sierra del Divisor, nr río Trapiche, 190 m, 7³'22"S, 746'51"W, 2022.ii.2009; (2) Sierra del Divisor, 2 km río Hubuya, 196 m, 659'31.8"S, 7359'26.07"W, 13-14.x.2008; (2) Sierra del Divisor, cerca de Sarayacu, 195 m, 657'21.06"S, 74¹'27.4"W, 10-11.x.2008; (2) Trompeteros, a 3 km de Río Corrientes , 177 m, 3¹6'30.4"S, 75³7'24.7"W, 2829.xi.2008; (1) Loreto: Maynas, Qda Aguablanca, 157 m, 255'45.3"S, 7448'20.8"W, 24.i.2009 (1) Calientillo (Contamana), 150 m, 10.v.1985; (1) río Urituyacu, 144 m, 4²'36"S, 75²9'24"W, 24.iii.2010; (1) Río Urituyacu, CCNN San Juan de Abejaico, $150 \mathrm{~m}, 4^{\circ} 05^{\prime} 25^{\prime \prime S}$, 760'36"W, 17.xi.2009; (1) río Copalyacu, $161 \mathrm{~m}$, $3^{\circ} 25^{\prime} 12^{\prime \prime S}, 75^{\circ} 15^{\prime} 36^{\prime \prime W}, 07-x i .2009$.

Comentario: Esta especie presenta un rango altitudinal entre 100 y 3400 m de altitud (Génier 2009, Camero y Lobo 2012. Su distribución está registrada en Bolivia, Brasil, Colombia, Ecuador y Perú; en este último ocurre en los departamentos de Huánuco, Loreto y Madre de Dios (Génier 2009), en el MUSM se encontraron individuos de Cusco, Junín, San Martin y Ucayali. En Loreto, la especie ha sido encontrada en enero, febrero, marzo, mayo, octubre y noviembre.

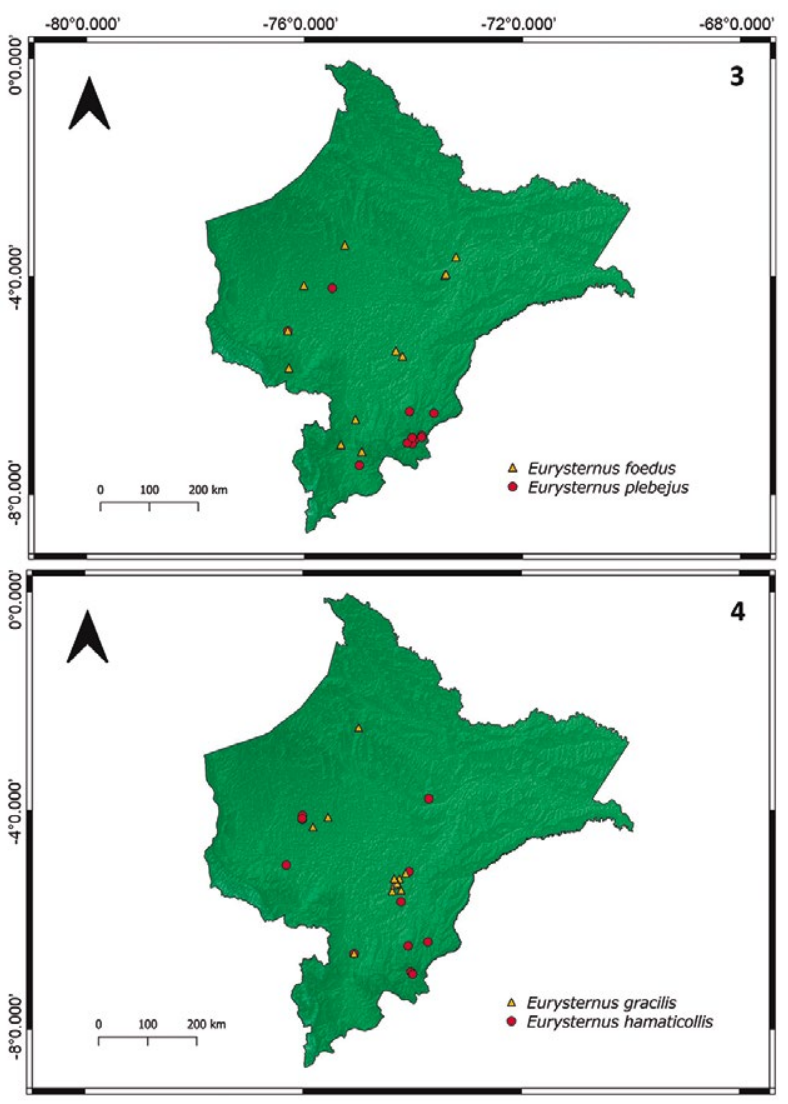

Figura 15. Mapa de distribución geográfica. 3) Eurysternus foedus y Eurysternus plebejus. 4) Eurysternus gracilis y Eurysternus hamaticollis. 


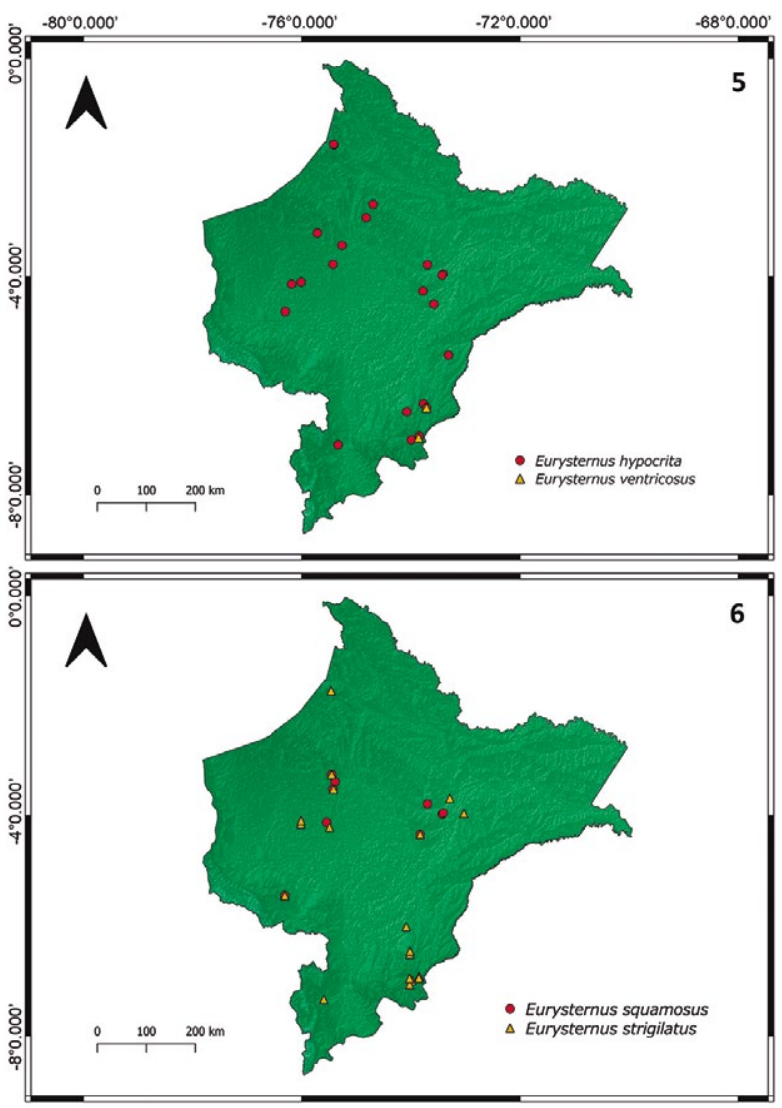

Figura 16. Mapa de distribución geográfica. 5) Eurysternus hypocrita y Eurysternus ventricosus. 6) Eurysternus squamosus y Eurysternus strigilatus.

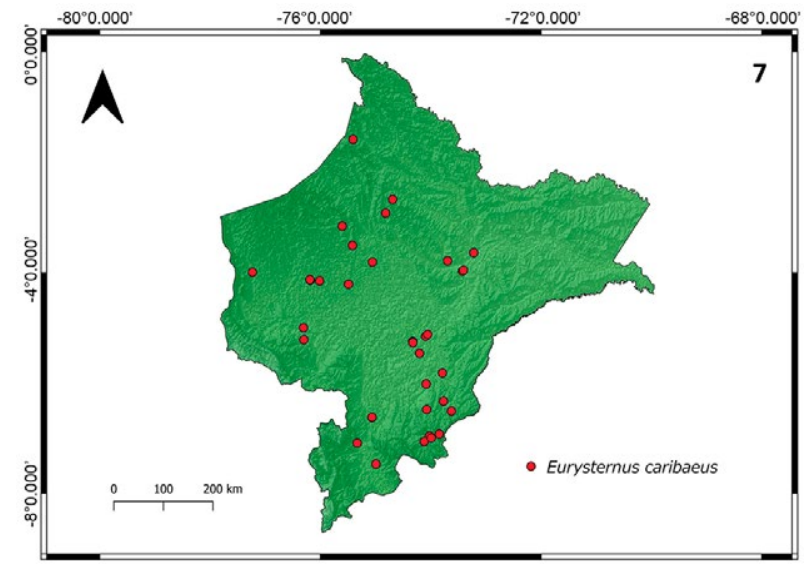

Figura 17. Mapa de distribución geográfica. 7) Eurysternus caribaeus.

\section{Discusión}

Se presentan 13 especies para Loreto, y un nuevo registro para Perú. Este nuevo registro incrementa el número de especies de Eurysternus para Perú a 20 especies (Ratcliffe et al. 2015), siendo el segundo país con mayor diversidad, después de Brasil que posee 35 especies (Vaz de Mello 2020), y por delante de Bolivia y Colombia con 18 especies (Génier 2009, Camero 2010), y Ecuador con 15 especies (Chamorro et al. 2018).
En cuanto al nivel de amenaza de las especies del género Eurysternus, podemos afirmar que la mayoría de especies tienen una presencia y abundancia importante en toda la Amazonía, posiblemente porque las especies son coprófagas generalistas, adaptándose fácilmente incluso al consumo de heces humanas. Sin embargo, sus poblaciones se verían afectadas por la fragmentación de bosques, ya que las especies de mayor tamaño necesitan las sombras producidas por los bosques.

\section{Literatura Citada}

Almeida LM, Mise KM. 2009. Diagnosis and key of the main families and species of South American Coleoptera of forensic importance. Revista Brasileira de Entomologia. 53(2):227-244. https://doi.org/10.1590/S008556262009000200006 .

Ampudia C, Estrella R. 2020. Efectividad de cebos en la captura de escarabajos saprófagos (Insecta: Coleoptera) en Allpahuayo Mishana, Amazonía peruana. Ciencia Amazónica (Iquitos). 8(1):71-84. https://doi. org/10.22386/ca.v8i1.281.

Ampudia C, Estrella R, Noriega J. 2012. New country record for Tetramereia convexa (Harold, 1869) (Coleoptera: Scarabaeidae: Scarabaeinae). Insecta Mundi. (270):1-4.

Ampudia C, Estrella R, Pérez P. 2020. Escarabajos coprófagos (Coleoptera: Scarabaeidae: Scarabaeinae) en bosques sobre arena blanca de la Reserva Nacional Allpahuayo Mishana, en la Amazonía peruana. Ciencia Amazónica (Iquitos). 8(1):53-70. https://doi.org/10.22386/ ca.v8i1.280.

Cambeforti Y, Hanski I. 1991. Dung Beetle Population Biology. In: Dung Beetle Ecology. Princeton, New Jersey: Princeton University Press. p. 481.

Camero E. 2010. Los escarabajos del género Eurysternus Dalman, 1824 (Coleoptera: Scarabaeidae) de Colombia. Boletín de la SEA. (46):147-179.

Camero E, Lobo JM. 2012. The distribution of the species of Eurysternus Dalman, 1824 (Coleoptera: Scarabaeidae) in America: potential distributions and the locations of areas to be surveyed. trcs. 5(2):225-244. https://doi. org/10.1177/194008291200500210.

Castelnau MLC de. 1840. Histoire Naturelle des Insectes Coléoptères. In: Histoire naturelle des animaux articulés, Annelides, Crustacés, Arachnides, Myriapodes et insectes. Paris: P. Duménil. p. 564.

Chamorro W, Marín-Armijos D, Granda V \& Vaz de Mello FZ. 2018. Listado de especies y clave de géneros y subgéneros de escarabajos estercoleros (Coleoptera: Scarabaeidae: Scarabaeinae) presentes y presuntos para Ecuador. Revista Colombiana de Entomología. 44(1): 72-100. https://doi.org/10.25100/socolen. v44i1.6545

Favila ME, Halffter G. 1997. The use of indicator groups for measuring biodiversity as related to community structure and function. Acta Zoológica Mexicana (nueva serie). (72): 1-25.

Figueroa L, Edmonds WD, Martínez Luján N. 2014. La tribu Phanaeini (Coleoptera, Scarabaeidae, Scarabaeinae) en el Perú. Revista Peruana de Biología. 21(2): 125138. https://doi.org/10.15381/rpb.v21i2.9815.

Figueroa L, Edmonds WD, Meza-Velez F. 2012. The genus Gromphas Brullé, 1837 in Peru (Coleoptera: Scarabaeidae: Scarabaeinae: Phanaeini). Insecta Mundi. (248): 1-8. 
Génier F. 2009. Le genre Eurysternus Dalman, 1824 (Scarabaeidae: Scarabaeinae: Oniticellini), révision taxonomique et clés de détermination illustrées. Sofia, Bulgaria: Pensoft Series Faunistica. 85: 430 pp.

Gill BD. 1990. Two new species of Eurysternus Dalman (Coleoptera: Scarabaeidae: Scarabaeinae) from Venezuela with notes on the genus. The Coleopterists Bulletin. 44(3): 355-361.

Guérin-Méneville FE. 1830. [1829-1844]: Iconographie du règne animal de $\mathrm{G}$. Cuvier, ou représentation d'après nature de l'une des espèces les plus remarquables, et souvent non encore fi gurées, de chaque genre d'animaux. Avec un texte descriptif mis au courant de la science. Ouvrage pouvant servir d'atlas à tous les traités de zoologie. II. Planches des Animaux Invertébrés. Paris: J.B. Baillière. 226 pls.

Guérin-Méneville FE. 1844 [1829-1844]: Iconographie du règne animal de G. Cuvier, ou représentation d'après nature de l'une des espèces les plus remarquables, et souvent non encore fi gurées, de chaque genre d'animaux. Avec un texte descriptif mis au courant de la science. Ouvrage pouvant servir d'atlas à tous les traités de zoologie. III. Texte Explicatif (Insectes) Paris: J.B. Baillière. $576 \mathrm{pp}$.

Harold E. 1880. Verzeichnis der von E. Steinheil in Neu-Granada gesammelten coprophagen Lamellicornien. Entomologische Zeitung. 41(1-3): 13-46.

Huerta C, Halffter G, Halffter V. 2005. Nidification in Eurysternus foedus Guérin-Méneville: its relationship to other dung beetle nesting patterns (Coleoptera: Scarabaeidae: Scarabaeinae). Folia Entomológica Mexicana. 44(1): 75-88.

Herbst JFW. 1789. Natursystem aller bekannten in- und ausländischen Insekten, als eine Fortsetzung der von Büffonschen Naturgeschichte. Nach dem System des Ritters von Linné und Fabricius zu bearbeiten angefangen von Carl Gustav Jablonsky von Johan Friedrich Wilhem Herbst. Der Käfer Theil. Berlin: Joachim Pauli. $330 \mathrm{pp}$.

Martinez A. 1988. Notas sobre Eurysternus Dalman (Coleoptera, Scarabaeidae). Entomologica Basiliensia. (12): 279-304.

Morrone, JJ. 2014. Biogeographical regionalization of the Neotropical region. Zootaxa. 3782(1): 1-110. https://doi. org/10.11646/zootaxa.3782.1.1

Nichols E, Larsen T, Spector S, Davis AL, Escobar F, Favila M, Vulinec K. 2007. Global dung beetle response to tropical forest modification and fragmentation: A quantitative literature review and meta-analysis. Biological Conservation. 137(1): 1-19. https://doi.org/10.1016/j. biocon.2007.01.023.

Nichols E, Spector S, Louzada J, Larsen T, Amezquita S, Favila ME. 2008. Ecological functions and ecosystem services provided by Scarabaeinae dung beetles. Biological Conservation. 141(6): 1461-1474. https://doi.org/10.1016/j.biocon.2008.04.011.

Pitman N, Gagliardi G, Jenkins C. 2013. La Biodiversidad de Loreto, Perú: El conocimiento actual de la diversidad de plantas y vertebrados terrestres. Center for International Environmental Law, Washington, DC, USA. 39 pp.

Ratcliffe BC, Jameson ML, Figueroa L, Cave RD, Paulsen MJ, Cano EB, Beza-Beza C, Jiménez - Ferbans L \& Reyes-Castillo P. 2015. Beetles (Coleoptera) of Peru: A Survey of the Families. Scarabaeoidea. Journal of the Kansas Entomological Society. 88(2): 186-207.
Sulca L, Huamantinco AA. 2016. Variación estacional de la comunidad de escarabajos Scarabaeinae (Coleoptera: Scarabaeidae) de un bosque inundable amazónico de Perú. Ecología Aplicada. 15(1): 47-55.

Vaz de Mello FZ. 2020. Scarabaeidae in Catálogo Taxonômico da Fauna do Brasil. PNUD. Access on: 07 Nov. 2020. http://fauna.jbrj.gov.br/fauna/faunadobrasil/128170.

Villareal H, Álvarez M, Córdoba S, Escobar F, Fagua G, Gast F, Mendoza H, Ospina N, Umaña AM. 2006. Insectos. In: Manual de métodos para el desarrollo de inventaríos de biodiversidad. Programa de Inventaríos de Biodiversidad. Segunda edición. Bogotá, Colombia: Instituto de Investigación de Recursos Biológicos Alexander von Humboldt. p. 236.

\section{Agradecimientos / Acknowledgments:}

Los autores agradecen a Biosfera Consultores Ambientales S.A.C. por el soporte en la realización de la investigación.

Conflicto de intereses / Competing interests:

Los autores declaran no incurrir en conflictos de intereses.

\section{Rol de los autores / Authors Roles:}

LF: conceptualización, investigación, escritura- preparación del borrador original, redacción: revisión y edición. FP partició en la investigación, escritura - preparación del borrador original, redacción: revisión y edición.

Fuentes de financiamiento / Funding:

Wildlife Conservation Society.

\section{Aspectos éticos / legales; Ethics / legals:}

Los autores declaran no haber incurrido en aspectos antiéticos, ni omitido normas legales en la realización de este trabajo. 